\title{
Identification, characteristics, and dynamics of Arctic extreme seasons
}

\author{
Katharina Hartmuth ${ }^{1}$, Maxi Boettcher ${ }^{1}$, Heini Wernli ${ }^{1}$, and Lukas Papritz ${ }^{1}$ \\ ${ }^{1}$ Institute for Atmospheric and Climate Science, ETH Zurich, Zurich, Switzerland
}

Correspondence: Katharina Hartmuth (katharina.hartmuth@env.ethz.ch)

\begin{abstract}
.
The Arctic atmosphere is strongly affected by anthropogenic warming leading to long-term trends in, e.g., surface temperature and sea ice extent. In addition, it exhibits a pronounced seasonal cycle and strong variability on time scales from days to seasons. Recent research elucidated processes causing short-term extreme conditions in the Arctic that are typically related to the occurrence of specific weather systems. This study investigates unusual atmospheric conditions in the Arctic on the seasonal time scale, characterized by surface temperature, surface precipitation, and the atmospheric components of the surface energy balance. Based on a principle component analysis in the phase space spanned by the seasonal-mean values of the considered parameters, individual seasons are then objectively identified that deviate strongly from a running-mean climatology, and that we define as extreme seasons. Given the strongly varying surface conditions in the Arctic, this analysis is done separately in Arctic sub-regions that are climatologically characterized by either sea ice, open ocean, or mixed conditions.
\end{abstract}

Using ERA5 reanalyses for the years 1979-2018, our approach identifies 2-3 extreme seasons for winter, spring, summer, and autumn, respectively, with strongly differing characteristics and affecting different Arctic sub-regions. While some show strongly anomalous seasonal-mean values mainly in one parameter, others are characterized by a combination of very unusual seasonal conditions in terms of temperature, precipitation, and the surface energy balance components. Two extreme winters affecting the Kara-Barents Seas are then selected for a detailed investigation of (i) their substructure, (ii) the role of synopticscale weather systems that occur during the season, and (iii) potential preconditioning by anomalous sea ice extent and/or sea surface temperature at the beginning of the season. Winter 2011/12 shows the highest surface temperature anomaly in parts of the Kara-Barents Seas (about $+5 \mathrm{~K}$ ), which was due to constantly above-average temperatures during the season related to a strongly enhanced frequency of blocking anticyclones in the Kara-Barents Seas and a strongly reduced frequency of cold air outbreaks. Sea ice coverage was normal at the beginning of the season and then developed a negative anomaly due to the unusually high temperatures. In contrast, winter 2016/17 started with a strongly negative anomaly in sea ice coverage and a strongly positive anomaly in sea surface temperature in the Kara-Barents Seas, which remained during most of the season. The combination of this preconditioning with specific synoptic conditions, i.e., a particularly high frequency of cold air outbreaks and an increased frequency of cyclones, was responsible for the extreme characteristics of this season, reflected in large upward surface heat flux anomalies and strongly increased precipitation. 
In summary, this study shows that extreme seasonal conditions in the Arctic are spatially heterogeneous, related to different near-surface parameters, and caused by different synoptic-scale weather systems, potentially in combination with surface preconditioning due to anomalous ocean and sea ice conditions at the beginning of the season. The framework developed in this study and the insight gained from analyzing the ERA5 period will be beneficial for addressing the effects of global warming on Arctic extreme seasons.

\section{Introduction}

Near-surface atmospheric conditions in the Arctic show a high variability on synoptic to inter-annual temporal scales, which is superimposed on a strong, long-term warming trend (e.g. Serreze and Barry, 2011; Cohen et al., 2014). Key drivers of variability on the synoptic to weekly time scale are interactions with the mid-latitudes for instance via air mass exchanges (e.g. Woods et al., 2013; Laliberté and Kushner, 2014; Graversen and Burtu, 2016; Messori et al., 2018; Papritz and Dunn-Sigouin, 2020) and air mass transformations within the Arctic (Ding et al., 2017; Pithan et al., 2018; Papritz, 2020). Both air mass exchanges and transformations are found to be related to synoptic weather systems. On longer time scales, in contrast, memory effects and feedback mechanisms such as the sea ice albedo feedback (Arrhenius, 1896; Curry et al., 1995), the water vapor and cloud feedbacks (Vavrus, 2004; Graversen and Wang, 2009; Boisvert et al., 2016), as well as the temperature feedback (Pithan and Mauritsen, 2014) play an important role. Given this broad spectrum of processes, this leads to the question how variability on various temporal scales is inter-connected. In this study, we focus on the seasonal scale and it is our goal to analyze the role of intra-seasonal processes, including synoptic-scale weather systems, for the emergence of seasonal extremes in the Arctic. The following paragraphs provide the relevant background on the key near-surface meteorological parameters in the Arctic and how they are interrelated. Furthermore, we discuss the role of different synoptic-scale weather systems for the variability of these parameters and the occurrence of short-term extremes and seasonal anomalies in the Arctic.

Near-surface temperature, the components of the surface energy budget - including radiative and turbulent heat fluxes - as well as surface precipitation are especially important parameters linking the variability of the atmosphere with that of the ocean and the cryosphere. Large fluctuations in the surface energy budget, which themselves are closely linked to air temperature fluctuations, contribute to the variability of sea ice (Stroeve et al., 2008; Olonscheck et al., 2019), the ocean mixed layer as well as open ocean convection (e.g. Marshall and Schott, 1999). Radiative and sensible heat fluxes drive the variability of the surface energy budget components over sea ice (Lindsay, 1998), whereas over open ocean turbulent heat fluxes dominate (Segtnan et al., 2011). Precipitation variability influences snow cover, which is strongly linked to the albedo feedback, and it affects the freshwater balance of the Arctic Ocean and the Nordic Seas (Serreze and Francis, 2006; White et al., 2007), which jointly with turbulent heat fluxes impacts the thermohaline circulation (Dickson et al., 1996; Talley, 2008).

The three parameters - near-surface temperature, surface energy budget, and surface precipitation - do not vary independently from each other but they are interlinked. Thereby, the surface boundary conditions, i.e., sea ice vs. open ocean, strongly affect 
the type of linkages between parameters and of the feedback processes due to vastly different heat capacities. On synoptic time scales, for instance, warm and cold air advection strongly influence heat fluxes over the open ocean, where the most intense upward fluxes occur in cold air outbreaks (Harden et al., 2015; Papritz and Spengler, 2017; Pope et al., 2020). On longer time scales, surface air temperature changes are largely influenced by variations in the sea surface temperature via surface sensible heat fluxes (Johannessen et al., 2016). In addition, incoming shortwave radiation is absorbed and can be released to the atmosphere later. Over sea ice, in contrast, temperature is to a large degree determined by the surface energy balance, which includes radiative and turbulent heat fluxes, conductive heat fluxes across the ice and latent energy for freezing and melting (Serreze and Francis, 2006). In winter, when the incoming shortwave radiation is strongly reduced, the surface sensible heat flux and net surface longwave radiation mainly determine the surface energy balance in regions covered by sea ice (Ohmura, 2012). These considerations reveal that a meaningful identification of extreme seasons in terms of the surface temperature, energy budget and precipitation parameters must take their co-variability and the underlying surface boundary conditions into account.

The role of synoptic-scale weather systems for inter-annual variability in the Arctic has been subject of multiple recent studies, which emphasized especially the importance of cyclones (Simmonds and Rudeva, 2012; Messori et al., 2018), blocking anticyclones (Wernli and Papritz, 2018; Papritz, 2020), and Rossby wave breaking (Liu and Barnes, 2015). Air mass exchanges between the mid-latitudes and the Arctic region are often facilitated by cyclones, which, on one hand, transport warm and moist air to higher latitudes (Sorteberg and Walsh, 2008; Messori et al., 2018), causing there an increase in downward heat fluxes as well as the formation of clouds and precipitation. On the other hand, the advection of cold and dry air in the cyclones' cold sector enhances ocean evaporation and heat fluxes into the atmosphere. Additionally, extreme moisture transport into the Arctic is often associated with events of Rossby wave breaking (Liu and Barnes, 2015), which can be strongly linked to the evolution of surface cyclones (Martius and Rivière, 2016). Air mass transformations within the Arctic can similarly result in anomalous conditions. Recent studies emphasized the importance of polar anticyclones and blocking events in the High Arctic, driving subsidence-induced adiabatic warming and thus leading to anomalies in surface temperature and net surface radiation, resulting in increased sea ice melting (Wernli and Papritz, 2018; Papritz, 2020). In winter, radiative heat loss under clear-sky conditions can lead to extreme cold conditions, whereas cloud formation favors the trapping of longwave radiation, thus providing a positive warming feedback and causing an increase in surface temperature (Boisvert et al., 2016; Woods and Caballero, 2016). Similarly, a persistent and strong tropospheric polar vortex over the pole can isolate polar air masses and result in anomalously cold conditions due to enhanced radiative cooling (Messori et al., 2018; Papritz, 2020). Therefore, air mass transport and air mass transformation can significantly influence the Arctic surface energy balance. Whereas the modification of turbulent heat fluxes is of particular importance over the open ocean, the impact on radiative fluxes, for instance due to an increase in the atmospheric moisture content, is highly relevant in regions covered by sea ice.

Several studies have analyzed short-term Arctic extreme events and the involved dynamical processes, for instance the un- 
https://doi.org/10.5194/wcd-2021-18

Preprint. Discussion started: 13 April 2021

(c) Author(s) 2021. CC BY 4.0 License.

(c) (i)

Weather and

Climate Dynamics

Discussions

and caused significant sea ice melting in the Kara-Barents Seas (Boisvert et al., 2016). Binder et al. (2017) were able to show that several pathways of exceptional air mass transport caused this warm event. Another example is an extreme melt event on the Greenland ice shield in July 2012 (Nghiem et al., 2012), which was found to be related to a blocking anticyclone and associated anomalous long-range transport of warm and humid air masses from the South (Hermann et al., 2020). Such extreme weather events can have significant long-term effects, particularly due to their impact on sea surface temperatures and sea ice extent. For instance, Simmonds and Rudeva (2012) have shown that a particularly intense Arctic cyclone in summer caused the dispersion and separation of sea ice, leaving the main sea ice pack more exposed and thus vulnerable to further melting. Similarly, the described extreme warm event in December 2015 caused positive anomalies in sea surface temperature and negative anomalies in sea ice concentration in the Kara-Barents Seas, which persisted throughout the year 2016 (Blunden and Arndt, 2017). Single events of extreme weather, causing episodes of strongly anomalous conditions such as exceptionally high or low surface temperatures, can thus have a major impact on seasonal-mean surface temperature, the formation and melting rates of sea ice, and on minimum and maximum sea ice extent.

Despite these insights, so far only little attention has been given to systematically understanding the characteristics of extreme seasonal-mean conditions in the Arctic, and the role of synoptic weather systems in their formation. Therefore, our study aims to address the following research questions:

1. How spatially (in)homogeneous are the seasonal-mean near-surface atmospheric conditions in the Arctic in winter and summer?

2. How can extreme seasons be defined objectively, based on a combined analysis of different key surface parameters in Arctic sub-regions?

3. Which dynamical processes, in particular, which synoptic-scale weather systems determine the sub-structure of extreme seasons?

4. What is the role of surface preconditioning, i.e., of early season anomalies of sea surface temperature and/or sea ice concentration for the formation of extreme seasons?

To address these research questions, a novel method will be introduced to determine the "unusualness" of a season, which we define based on a combination of various surface parameters. Our study is organized as follows: Data and methods are described in Section 2. Section 3 presents an overview of the seasonal variability of surface temperature, surface precipitation, and of the surface energy budget components. In Section 4 we define anomalous and extreme seasons in the Arctic based on seasonal anomalies of these parameters, and analyze their substructure in distinct Arctic sub-regions. Detailed analyses of three Arctic extreme seasons and the involved atmospheric synoptic-scale processes are presented in Section 5, followed by the main conclusions in Section 6. 


\section{Data and method}

\subsection{ERA5 data}

To perform a detailed analysis of Arctic extreme seasons, the ERA5 reanalysis dataset of the European Centre for MediumRange Weather Forecasts (ECMWF) is used (Hersbach et al., 2020). Hourly atmospheric fields and short-range forecasts were spatially interpolated to a $0.5^{\circ} \times 0.5^{\circ}$ horizontal grid on model levels. The study period includes winters [DecemberFebruary (DJF)] from 1979/80 to 2017/18 as well as springs [March-May (MAM)], summers [June-August (JJA)] and autumns [September-November (SON)] from 1980 to 2018. Based on the ERA5 dataset, we additionally consider synoptic features such as extratropical cyclones and blocks identified following the methods presented in Sprenger et al. (2017).

Further, we define cold air outbreaks (CAOs) based on the exceedance of the $900 \mathrm{hPa}$ sea-air potential temperature difference $\left(\theta_{S S T}-\theta_{900}\right)$ by $+4 \mathrm{~K}$ (cf. Papritz and Spengler, 2017), whereby we exclude grid points over land or with a sea ice concentration of more than $50 \%$. As outlined below, particularly anomalous seasons are identified based on seasonal-mean anomalies of the following six variables in specific regions: $2 \mathrm{~m}$ temperature $\left(T_{2 m}\right)$, precipitation $(P$, defined as the sum of convective and large-scale precipitation), surface sensible heat flux $\left(H_{S}\right)$, surface latent heat flux $\left(H_{L}\right)$, net surface shortwave radiation $\left(R_{S}\right)$ and net surface longwave radiation $\left(R_{L}\right)$. The last four variables are relevant for the surface energy balance and their sum is denoted by $E_{S}$. We use short-range forecasts for the fluxes $P, H_{S}, H_{L}, R_{S}$ and $R_{L}$ and analyses for the other fields.

Abbreviation
$H_{L}$
$H_{S}$
$P$
$R_{L}$
$R_{S}$
$\mathrm{SIC}$
$\mathrm{SST}$
$T_{2 m}$

Variable name
surface latent heat flux
surface sensible heat flux
precipitation
net surface longwave radiation
net surface shortwave radiation
sea ice concentration
sea surface temperature
$2 \mathrm{~m}$ temperature

Unit

$\left[\mathrm{W} \mathrm{m}^{-2}\right]$

$\left[\mathrm{W} \mathrm{m}^{-2}\right]$

$\left[\mathrm{mm}\right.$ day $^{-1}$ ]

$\left[\mathrm{W} \mathrm{m}^{-2}\right]$

$\left[\mathrm{W} \mathrm{m}^{-2}\right]$

$[\mathrm{K}]$

Table 1. List of variable names used in this study.

To compute anomalies, a transient climatology is calculated at every grid point as follows. First, daily-mean values of the variables are smoothed with a 21-day running mean filter. In a second step, the 9-year running mean is computed for each calendar day. Thus, the seasonal cycle is retained in the climatology, but decadal variations and long-term trends related to the overall warming of the Arctic are removed. The climatology is kept constant at the beginning and end of the study period when no 9-year running mean can be calculated. Examples of this filtering procedure are shown in the supplementary material, where Fig. S1a and b shows the original $T_{2 m}$ time series in the Kara-Barents Seas and illustrates that the 9-year running mean can 
https://doi.org/10.5194/wcd-2021-18

Preprint. Discussion started: 13 April 2021

(C) Author(s) 2021. CC BY 4.0 License.

effectively eliminate also non-linear long-term trends $\left(T_{2 m}\right.$ in the Kara-Barents Seas steeply increases in the decade from 2000 2010). Seasonal-mean anomalies are then defined as deviations of the seasonal-mean values from this transient climatology. With this approach (also used by Messori et al. (2018) and Papritz (2020)), the identified extreme seasons appear relatively uniform throughout the study period (see Table 2 and Tables S1-S4 in the supplementary material). Throughout the study, we denote daily anomalies of a variable $\chi$ as $\chi^{*}$, seasonal-mean anomalies as $\overline{\chi^{*}}$ and seasonal-mean absolute anomalies as $\overline{\left|\chi^{*}\right|}$.
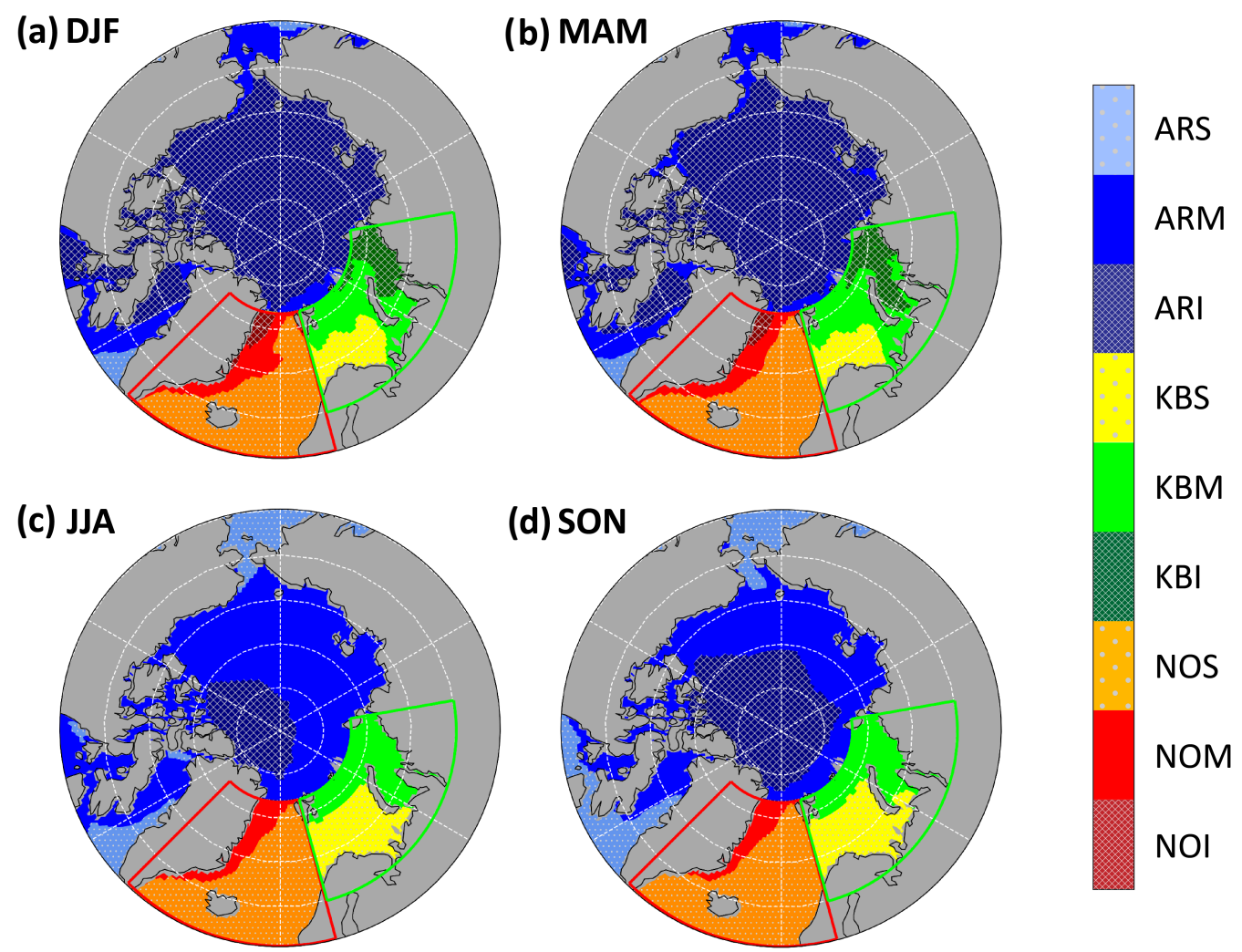

Figure 1. Sub-regions defined based on $\mathrm{SIC}_{\text {clim }}$ in (a) DJF, (b) MAM, (c) JJA, and (d) SON. The labels refer to: NOI: Nordic Seas Ice, NOM: Nordic Seas Mixed, NOS: Nordic Seas Sea, KBI: Kara-Barents Seas Ice, KBM: Kara-Barents Seas Mixed, KBS: Kara-Barents Seas Sea, ARI: Arctic Residual Ice, ARM: Arctic Residual Mixed, ARS: Arctic Residual Sea.

\subsection{Definition of sub-regions}

It is one goal of this study to analyze the characteristics of Arctic extreme seasons with respect to climatological conditions. Therefore, extreme seasons will be identified in three distinct regions, the Nordic Seas (NO), the Kara-Barents Seas (KB) and the remaining Arctic poleward of $60^{\circ} \mathrm{N}$ (AR, containing the High Arctic region $>80^{\circ} \mathrm{N}$ ). Grid points above land are excluded. As the variables, especially the surface heat fluxes and surface radiation are strongly dependent on the surface conditions (e.g. 
Pope et al., 2020), the regions are additionally subdivided in each season according to the climatological seasonal-mean sea ice concentration $\left(\mathrm{SIC}_{\text {clim }}\right)$. A distinction is made between areas where, on all days of the considered season in the entire ERA5 time period, mainly sea ice is present (Ice, $\left.\mathrm{SIC}_{\text {clim }}>0.9\right)$, mainly open ocean is present (Sea, $\mathrm{SIC}_{\text {clim }}<0.1$ ), and regions of intermediate $\mathrm{SIC}_{\text {clim }}$ (Mixed, $0.1 \leq \mathrm{SIC}_{\text {clim }} \leq 0.9$ ). Furthermore we require a minimum size of a sub-region of $10^{5} \mathrm{~km}^{2}$. With these criteria, three sub-regions are defined in each region, which results in overall seven distinct sub-regions in JJA and SON and nine distinct sub-regions in DJF and MAM (Fig. 1). For example, ARM denotes the sub-region with intermediate sea ice cover in the High Arctic and NOS the sub-region with mainly open ocean in the Nordic Seas. In these sub-regions and based on the surface parameters listed above, anomalous and extreme Arctic seasons are defined using a method based on principal component analysis (PCA) as detailed in the following.

\subsection{Definition of anomalous and extreme seasons}

To determine in an objective way whether a season is anomalous or extreme, a PCA is performed for each sub-region. For that purpose, the seasonal anomalies of the six variables (referred to as precursors) are standardized with their inter-seasonal standard deviation to ensure comparability and equal weighting of the different parameters. Here, the variables $H_{S}, H_{L}, R_{S}$ and $R_{L}$, which all contribute to the surface energy balance $\left(E_{S}\right)$, are weighted by the maximum standard deviation of the four $E_{S}$ components, thus emphasizing variables contributing stronger to $E_{S}$ variability. We use the PCA to reduce the dimensionality of the six-parameter phase space to two dimensions by focusing on the first and second principal component $(\widetilde{P C 1}$ and $\widetilde{P C 2})$. $\widetilde{P C 1}$ and $\widetilde{P C 2}$ maximize the so-called "explained variance", which is the explained proportion of the total inter-seasonal variability in the six-dimensional phase space of the precursors.

To define extreme and anomalous seasons, $\widetilde{P C 1}$ and $\widetilde{P C 2}$ are first rescaled by their respective standard deviation $\left(\sigma_{1}\right.$ and $\sigma_{2}$ ), such that outliers in both PCs are treated similarly independent of the variance explained by $\widetilde{P C 1}$ and $\widetilde{P C 2}$, thus providing a measure for the unusualness of each season with respect to each of the principal components (from now on, we will refer to these rescaled components as $P C 1$ and $P C 2$ ). Then, the Euclidian distance in the reduced phase space spanned by the two rescaled components, the so-called "Mahalanobis distance" $\left(d_{M}\right)$, is calculated as:

$d_{M}=\sqrt{P C 1^{2}+P C 2^{2}}=\sqrt{\frac{\widetilde{P C 1}^{2}}{\sigma_{1}^{2}}+\frac{\widetilde{P C 2}^{2}}{\sigma_{2}^{2}}}$

This measure $d_{M}$ can now be used to quantify how strongly a particular season deviates from climatology, representing the combination of the seasonal anomalies of the six variables. We therefore refer to $d_{M}$ as "anomaly magnitude" of a particular season. Seasons with $d_{M} \geq 3$ are defined as "extreme seasons", and seasons with $3>d_{M} \geq 2$ as "anomalous seasons". 


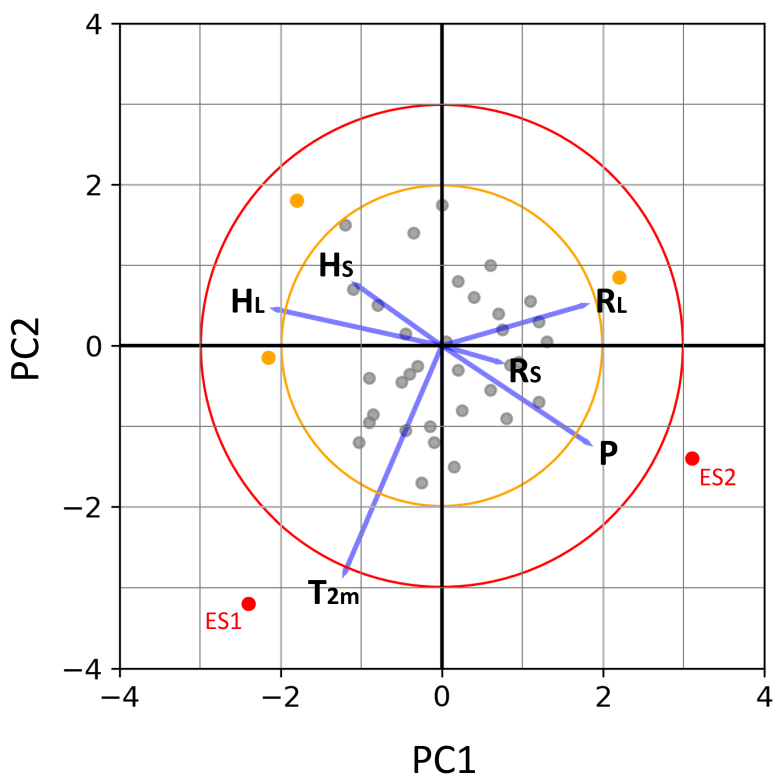

Figure 2. Schematic PCA biplot for a specific region and season with PC1 along the x-axis and PC2 along the y-axis. Grey dots represent single seasons, red (orange) dots show extreme (anomalous) seasons. Blue lines represent the projections of the original parameters onto the first two principal components. Values of $d_{M}=2$ and $d_{M}=3$ are shown by orange and red circles, respectively.

The phase space of the rescaled principal components can be illustrated using a biplot (Fig. 2), similar as in Graf et al. (2017). The axes of such a plot represent PC1 and PC2, respectively, and each dot represents one season in the study period, whereby anomalous and extreme seasons are shown as colored dots. The closer two dots are, the more similar are the anomalies of the corresponding seasons. Radial vectors show the relative contribution of the precursor variables to PC1 and PC2, whereby the projected values of a vector on both axes illustrates the weight on the respective PC. In the case shown in Fig. 2 , the vector for $T_{2 m}$ is mainly aligned along PC2, thus $T_{2 m}$ variability is important for the second principal mode of variability in the six-dimensional phase space. Relatively longer (shorter) vectors indicate a larger (smaller) contribution of the precursor to the explained variance. If two vectors are approximately perpendicular, the precursors are uncorrelated. This interpretation of correlations is more precise, the higher the explained variance by PC1 and PC2 (Gabriel, 1971, 1972). The relative position of each season in the biplot (i.e., the scores) with respect to the precursor vectors indicates the contribution of the different precursor variables to the anomaly magnitude $d_{M}$ in the considered season. For instance, seasons with a positive $T_{2 m}$ anomaly are positioned in the direction of the $T_{2 m}$ vector and seasons with a negative $T_{2 m}$ anomaly in the opposite direction.

In the example given in Fig. 2, the variables $T_{2 m}$ and $P$ show no correlation, whereas $H_{S}$ and $H_{L}$ are positively correlated and $H_{S}$ and $P$ are strongly anti-correlated. Further, $T_{2 m}$ shows the largest contribution to the variance explained by PC1 and 
PC2 (mainly determining PC2) whereas $H_{L}, R_{S}$ and $R_{L}$ mostly contribute to PC1. $R_{S}$ contributes the least to the explained variance. Two seasons with $d_{M} \geq 3$ are marked as extreme season 1 (ES1) and extreme season 2 (ES2). Their score vectors are roughly orthogonal to each other, which indicates that a different combination of anomalies and thus different processes are decisive for explaining their large anomaly magnitudes. In this example, ES1 is mainly determined by a positive $T_{2 m}$ anomaly, while ES2 is an anomalously wet season with negative surface heat flux anomalies, as the respective precursor vectors are directed more or less directly towards $(P)$ respectively away $\left(H_{L}, H_{S}\right)$ from ES2.

\section{Spatial and temporal variability of Arctic seasons}

210 In order to characterize Arctic seasons in general, we first analyze the regional and temporal variability of seasonal-mean anomalies of surface temperature $\left(\overline{T_{2 m}{ }^{*}}\right)$, precipitation $\left(\overline{P^{*}}\right)$ and surface energy balance $\left(\overline{E_{S}{ }^{*}}\right)$, considering the varying surface conditions of the different sub-regions (Fig. 3). We are interested in correlations between the seasonal anomalies, how their magnitudes vary between the regions, and in aspects of the seasonal substructure (e.g., is an anomalously warm season constantly warm?).

In winter, warm seasons are generally wetter and cold seasons are drier (Fig. 3a). $\overline{E_{S}{ }^{*}}$ and $\overline{T_{2 m}{ }^{*}}$ are positively correlated, thus warm winters show in general a positive $\overline{E_{S}{ }^{*}}$ and vice versa for cold winters, whereby for the relationship between $\overline{E_{S^{*}}}$ and $\overline{P^{*}}$ a strong dependency on the respective surface type can be observed. In regions with $\mathrm{SIC}_{\text {clim }}>0.9, \overline{T_{2 m}{ }^{*}}$ and $\overline{P^{*}}$ are strongly positively correlated, thus warm winters are almost always wet and tend to have a positive $E_{S}$ anomaly (and again vice versa for cold winters). In contrast, regions with $\mathrm{SIC}_{\text {clim }}<0.1$ in the Nordic and Kara-Barents Seas do either show no or a slightly negative correlation between $\overline{T_{2 m}{ }^{*}}$ and $\overline{P^{*}}$. Over the open ocean, warm and dry winters show strongly positive, and cold and wet winters negative $\overline{E_{S}{ }^{*}}$ values. Regions with intermediate sea ice extent do not show this correlation between $\overline{T_{2 m} *}$ and $\overline{E_{S}{ }^{*}}$, but warm winters tend to be wet and cold winters dry, similar to the ice sub-regions.

In summer, no correlation between $\overline{T_{2 m}{ }^{*}}$ and $\overline{P^{*}}$ is found, but warm summers usually show a positive $\overline{E_{S}{ }^{*}}$ and cold summers a negative $\overline{E_{S}{ }^{*}}$, independent of the surface conditions (Fig. 3b). Regional differences are much smaller during summer, indicating more homogeneous conditions among the sub-regions. 

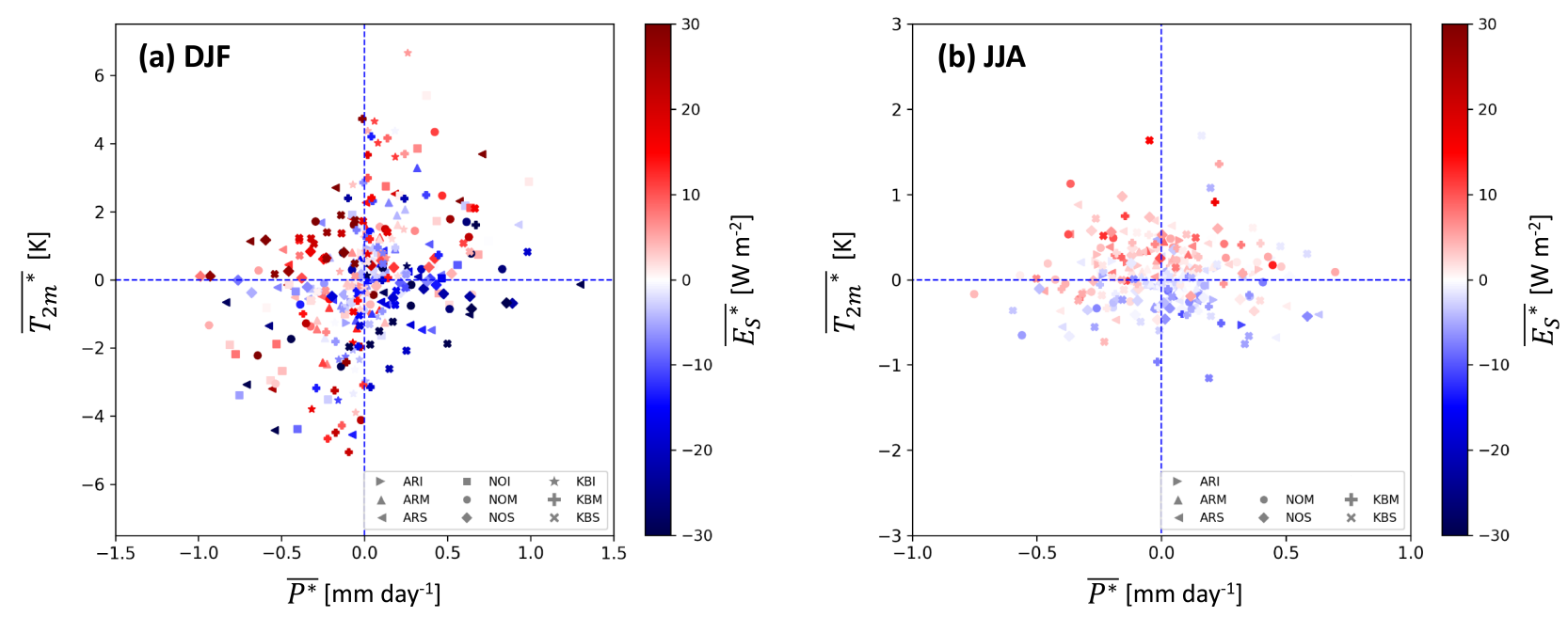

Figure 3. Seasonal-mean anomalies of $P\left(\overline{P^{*}} ; \mathrm{mm} \mathrm{day}^{-1}\right.$, along x-axis $), T_{2 m}\left(\overline{T_{2 m}{ }^{*}} ; \mathrm{K}\right.$, along y-axis $)$ and $E_{S}\left(\overline{E_{S}{ }^{*}} ; \mathrm{W} \mathrm{m}^{-2}\right.$, color $)$ for 39 seasons and (a) 9 sub-regions in DJF and (b) 7 sub-regions in JJA.

Figure 4 shows the seasonal-mean absolute anomalies $\overline{\left|T_{2 m^{*}}\right|}, \overline{\left|P^{*}\right|}$ and $\overline{\left|E_{S}{ }^{*}\right|}$, which are defined as the seasonal mean of the absolute daily anomalies. They are used as a measure for the overall variability of the individual parameters throughout a season. Distinct clusters occur for the different sub-regions in winter (Fig. 4a). Regions in high latitudes and mostly over sea ice such as ARI and ARM show only small variations in all three variables implying a relatively small amplitude of day-to-day and inter-seasonal fluctuations. In the Kara-Barents Seas, sub-regions KBI and KBM show high variability in daily and seasonal $T_{2 m}$ and $E_{S}$ anomalies but a similarly small $\overline{\left|P^{*}\right|}$. In the Nordic Seas, $T_{2 m}$ and $P$ are much more variable, except over the open ocean, where $T_{2 m}$ anomalies are typically smaller and less variable. $P$ and especially $E_{S}$ variability is strongly enhanced over the open ocean due to intensified air-sea interaction. The clear distinction of the seasonal-mean absolute anomalies between the different sub-regions reveals the spatial inhomogeneity of Arctic meteorological conditions in winter, which is due to varying surface conditions as well as differences in seasonal variability between distinct Arctic Seas. This also serves as an a posteriori confirmation of our approach to separately consider Arctic extreme seasons in these sub-regions.

In summer, the variability of the three analyzed parameters is smaller due to reduced meridional gradients of surface temperature and radiation causing smaller $T_{2 m}$ and $E_{S}$ fluctuations (Fig. 4b). Similar to winter, a large variability of $T_{2 m}$ occurs in the Kara-Barents Seas and of $P$ in the Nordic Seas. However, as the surface conditions between the sub-regions become more homogeneous, the regions do not appear in distinct clusters as for winter with the exception of the sub-regions ARI and ARM, which cover most of the perennial sea ice and show, as in winter, only a small variability of the three parameters. It is further noteworthy that $\overline{\mid T_{2 m^{*} \mid}}$ and $\overline{\left|P^{*}\right|}$ are positively correlated, indicating higher variability in $P$ in seasons with larger $T_{2 m}$ fluctuations. 

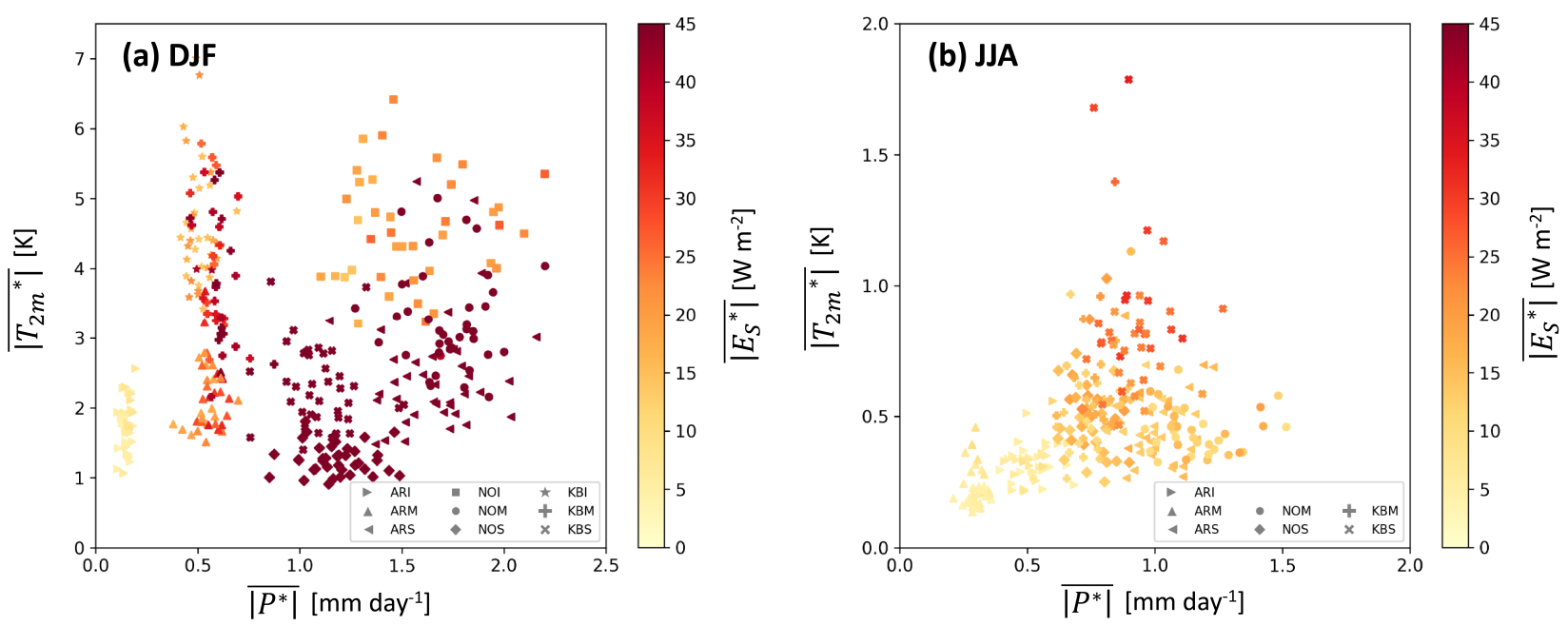

Figure 4. Seasonal-mean absolute anomalies of $P\left(\overline{\left|P^{*}\right|} ; \mathrm{mm} \mathrm{day}^{-1}\right.$, along x-axis $), T_{2 m}\left(\overline{\left|T_{2 m}{ }^{*}\right|} ; \mathrm{K}\right.$, along y-axis $)$ and $E_{S}\left(\overline{\left|E_{S}{ }^{*}\right|} ; \mathrm{W} \mathrm{m}^{-2}\right.$, color) for 39 seasons and (a) 9 sub-regions in DJF and (b) 7 sub-regions in JJA.

To better understand the seasonal substructure of Arctic winters and summers, we compare the seasonal-mean anomalies with the seasonal-mean absolute anomalies for $T_{2 m}, P$ and $E_{S}$ in selected sub-regions in DJF (Fig. 5) and JJA (Fig. 6). The ratio of seasonal-mean and seasonal-mean absolute anomalies is indicative for the temporal persistency of an anomaly throughout a season, thus the location of a season in the diagrams provides information about the substructure of the season in terms of the considered parameter. For instance, the further to the right, the more positive is the seasonal-mean anomaly of the shown parameter, and the further to the top, the larger is the seasonal-mean absolute anomaly. If the seasonal-mean anomaly is close to the seasonal-mean absolute anomaly (dots along the grey line), the more persistent is the anomaly during the season. For example, a season can be anomalously warm, because the daily-mean $T_{2 m}$ values are continuously larger than

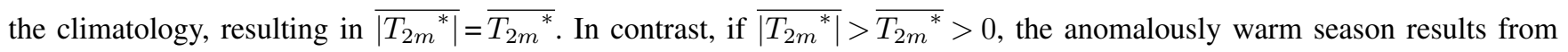
several warm episodes alternating with weaker and/or shorter periods with negative $T_{2 m}{ }^{*}$ values. If the seasonal-mean absolute anomaly is much larger compared to the seasonal-mean anomaly, i.e., $\overline{\left|T_{2 m}{ }^{*}\right|} \gg \overline{T_{2 m}{ }^{*}}$, then the variability of $T_{2 m}$ is large with several intense warm and cold episodes, which cancel each other out leading to a weak overall seasonal anomaly. 


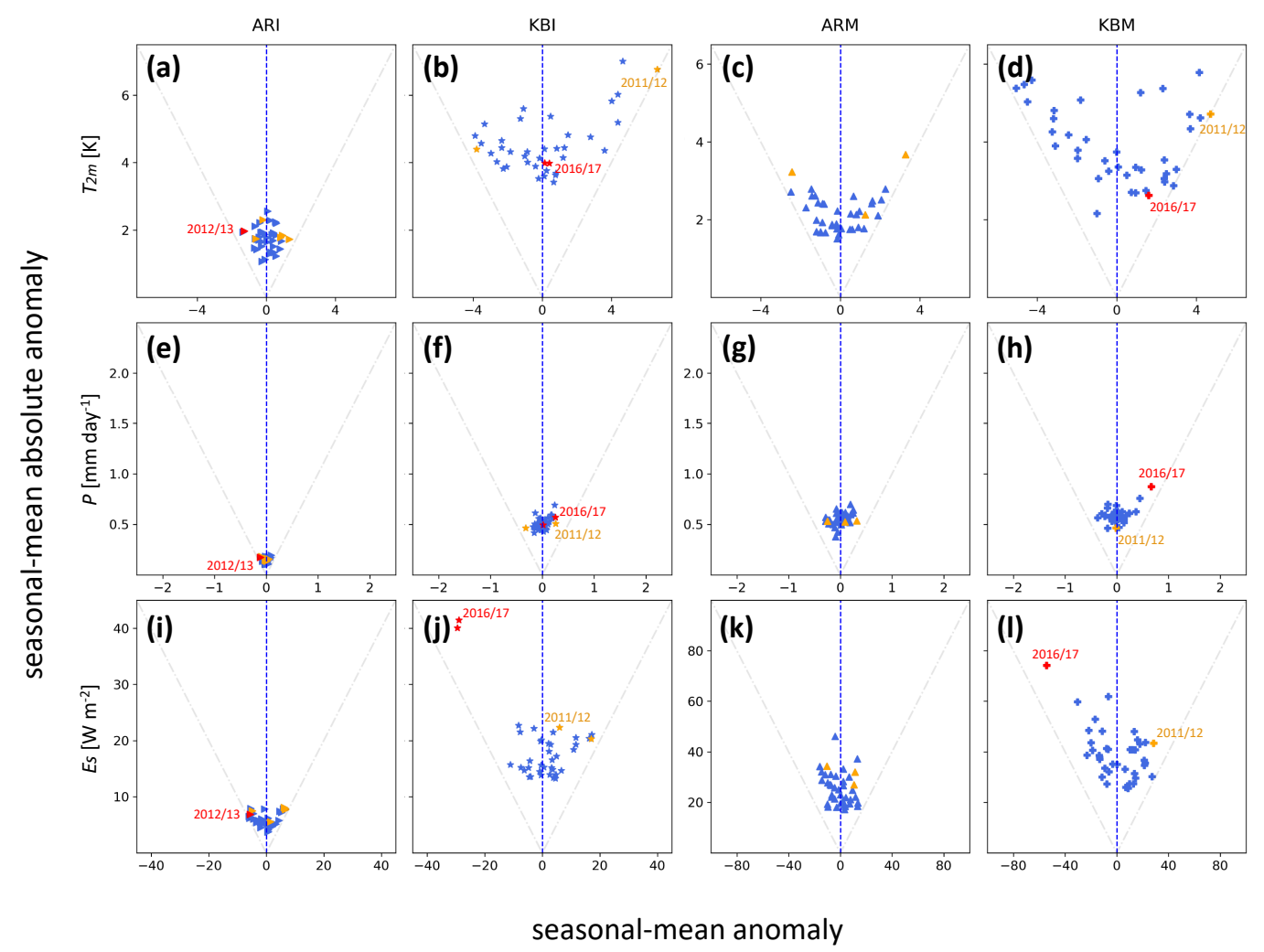

Figure 5. Seasonal-mean anomalies (along X-axis) vs. seasonal-mean absolute anomalies (along y-axis) in DJF for (a-d) $T_{2 m}$ (K), (e-h) $P\left(\mathrm{~mm} \mathrm{day}^{-1}\right)$, and (i-l) $E_{S}\left(\mathrm{~W} \mathrm{~m}^{-2}\right)$ in sub-regions ARI, KBI, ARM and KBM. Red (orange) markers represent extreme (anomalous) seasons (see Sect. 2.3) and selected case study seasons are labeled. The stippled grey line marks where the seasonal-mean anomaly equals the seasonal-mean absolute anomaly.

The seasonal substructures of the three parameters differ. In particular during summer, several seasons show continuous $T_{2 m}{ }^{*}$ (Fig. 6a-d) and/or almost continuous $E_{S}{ }^{*}$ values (Fig. 6i-1), including several clear outlier seasons in terms of $\overline{T_{2 m}{ }^{*}}$ (Fig. 6a, c, d). In winter, the overall $T_{2 m}$ variability is much larger and only very few seasons show distinct $\overline{T_{2 m}{ }^{*}}$ outliers (Fig. 5a-d). Further, no continuous $P^{*}$ can be observed (Figs. 5e-h and 6e-h), indicating that also in very wet seasons precipitation is episodic and includes dry periods. In addition, and maybe less evident, also the driest seasons feature some precipitation events.

The influence of the different surface conditions becomes apparent in particular for the seasonal substructure of $E_{S}$ anomalies. In regions with intermediate or high $\mathrm{SIC}_{\text {clim }}$, where surface heat fluxes are small and $E_{S}$ is mainly determined by net surface radiation, seasonal anomalies can continuously have the same sign, especially in summer, as shown by points near the diagonal in Fig. 6i and j. Over the open ocean, where surface heat fluxes are much more important, daily-mean $E_{S}$ values 
https://doi.org/10.5194/wcd-2021-18

Preprint. Discussion started: 13 April 2021

(c) Author(s) 2021. CC BY 4.0 License.

(c) (1)

Weather and

Climate Dynamics

Discussions

270 fluctuate significantly around the climatology, which results in a large $\overline{\left|E_{S}{ }^{*}\right|}$ but only a small $\overline{E_{S}{ }^{*}}$ (Fig. 61).

In KBM and KBS, a different distribution of $E_{S}$ anomalies occurs in DJF and JJA. Winters with a negative $\overline{E_{S}{ }^{*}}$, which is often caused by several episodes of cold air outbreaks (Papritz and Spengler, 2017), tend to show enhanced $E_{S}$ variability throughout the season (Fig. 5l) compared to winters with a positive $\overline{E_{S}{ }^{*}}$, where CAOs are less frequent. The opposite occurs in summer, when periods of increased net surface radiation can cause a positive $\overline{E_{S}{ }^{*}}$ and enhanced $\overline{\left|E_{S}{ }^{*}\right|}$ compared to seasons with a negative $\overline{E_{S}{ }^{*}}$ (Fig. 6k and 1).

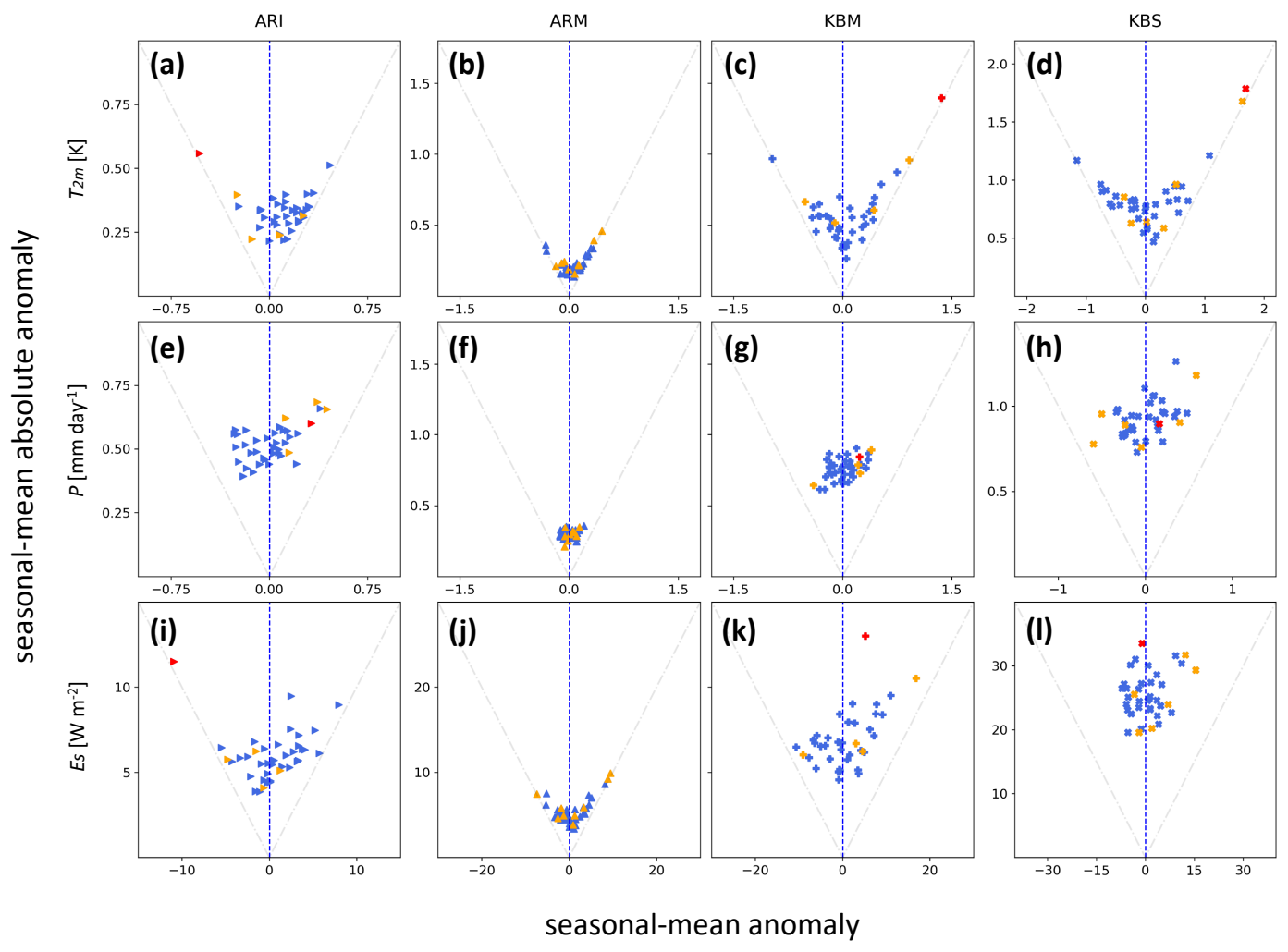

Figure 6. Same as Fig. 5 but for JJA in sub-regions ARI, ARM, KBM and KBS.

\section{PCA results}

In a next step, we identify and then characterize anomalous Arctic seasons, based on the combination of the seasonal-mean anomalies of the three surface parameters discussed above. To this end, a PCA is performed for each season (DJF, MAM, JJA, SON) and sub-region, as explained in Sect. 2.3. Figures 7 and 8 show the resulting biplots for DJF and JJA (for MAM and SON see Figs. S2 and S3 in the supplementary material). Depending on the region and sub-region, the contributions of the precursor 
variables to the principal components PC1 and PC2 vary, which usually explain about $80-90 \%$ of the total variance in the combined seasonal anomalies.

285 In winter, sub-regions over ice show a positive correlation between $\overline{T_{2 m}{ }^{*}}$ and $\overline{P^{*}}$ (Fig. 7a, d, g). This correlation is particularly strong in the High Arctic, where precipitation events during winter are predominantly caused by synoptic weather systems that transport warm and moist air masses into the region (e.g. Webster et al., 2019; Papritz and Dunn-Sigouin, 2020). $\overline{T_{2 m}{ }^{*}}, \overline{P^{*}}$ and $\overline{R_{L}{ }^{*}}$ mainly determine $\mathrm{PC} 1$ and thus the direction of maximum variance in the phase space spanned by all precursor variables in ice sub-regions. Surface sensible and latent heat flux anomalies are positively correlated and mostly uncorrelated with $\overline{T_{2 m}{ }^{*}}$ and $\overline{P^{*}}$ as they contribute mostly to PC2.

Similarly, sub-regions with intermediate sea ice concentration show a positive correlation of $\overline{T_{2 m}{ }^{*}}$ and $\overline{P^{*}}$ (Fig. 7b, e, h), although slightly weaker than over ice for regions KB and NO. Again, the heat fluxes are mostly uncorrelated with $\overline{T_{2 m}{ }^{*}}$ and slightly negatively correlated with $\overline{P^{*}}$, particularly $\overline{H_{L}{ }^{*}} \cdot \overline{R_{L}{ }^{*}}$ is contributing less to the variance in mixed regions, which indicates a comparatively lower importance of radiation compared to heat fluxes for determining the seasonal variability.

Over the open ocean (Fig. 7c, f, i), a positive correlation between the heat flux anomalies and $\overline{T_{2 m}{ }^{*}}$ can be observed, indicating increased surface fluxes from the ocean into the atmosphere during periods with anomalously cold temperatures. Unlike over ice, the maximum variance over open water is mainly determined by the surface heat fluxes. $\overline{P^{*}}$ is mostly uncorrelated to the other variables and strongly related to PC2, reflecting that precipitation can occur in warm conditions (e.g., warm sector of a cyclone) and in cold conditions (CAO).

Arctic summer seasonal variability is mainly determined by $\overline{T_{2 m}{ }^{*}}, \overline{P^{*}}$ and $\overline{R_{S}{ }^{*}}$, whereby $\overline{T_{2 m}{ }^{*}}$ and $\overline{P^{*}}$ are mostly uncorrelated in all regions (Fig. 8). Whereas $\overline{T_{2 m}{ }^{*}}$ shows only weak correlations with other parameters in general, $\overline{P^{*}}$ is strongly anti-correlated with $\overline{R_{S}{ }^{*}}$ in sub-regions NOS and ARS (Fig. $8 \mathrm{f}$ and i), most likely due to the presence of clouds during precipitation events. In sub-regions ARI and ARM (Fig. $8 \mathrm{~g}$ and $\mathrm{h}$ ), $\overline{R_{L}{ }^{*}}$ additionally influences the seasonal variability and strongly correlates with $\overline{T_{2 m}{ }^{*}}$, again emphasizing the importance of clouds in this region. 
https://doi.org/10.5194/wcd-2021-18

Preprint. Discussion started: 13 April 2021

(C) Author(s) 2021. CC BY 4.0 License.
Weather and

Climate Dynamics

Discussions

$\begin{array}{lll}\overline{\mathbf{P}^{*}}\left[\mathrm{~mm} \mathrm{day}^{-1}\right] & \overline{\mathbf{E}_{\mathrm{S}}{ }^{*}}\left[\mathrm{~W} \mathrm{\mathbf {m } ^ { - 2 }}\right] & \text { Area } \\ & {\left[10^{5} \mathbf{k m}^{2}\right]}\end{array}$

$+1.30(+2.73) \quad-47.10(-2.00) \quad 3.5$

DJF 2004/05 AR

$3.2-0.13(-0.07)$

$+0.02(+0.12)$

$-29.48(-3.07)$

5.3

DJF 2016/17 KBI

$3.0+0.13(+0.05)$

$+0.25(+1.96)$

$-29.00(-3.02)$

KBM

$3.4+0.41(+0.16)$

+0.67 (+3.44)

$-54.20(-3.03)$

KBS

$3.1+0.83(+0.65)$

$+0.98(+3.03)$

$-19.14(-0.81)$

$\begin{array}{llll}\text { JJA 2013 } & \text { ARI } & 3.2 & -0.53(-2.90) \\ \text { JJA 2016 } & \text { KBM } & 3.1 & +1.36(+3.27) \\ & \text { NOM } & 3.3 & +1.13(+3.47)\end{array}$

$+0.32(+1.75)$

$-10.9(-3.21)$

14.3

$+0.23(+1.18)$

$+0.52(+0.91)$

16.7

$-0.37(-1.10)$

$+9.27(+1.65)$

$\begin{array}{llll}\text { MAM 1990 } & \text { NOI } & 3.7 & +0.37(+0.27) \\ & \text { ARI } & 4.1 & +3.08(+3.45) \\ \text { MAM 1996 } & \text { NOM } & 3.3 & +1.32(+1.20\end{array}$

$-0.16(-0.37)$

$-1.51(-0.47)$

82.2

$+0.25(+3.81)$

$+2.36(+1.23)$

$-0.54(-1.25)$

$+33.96(+2.69)$

5.8

$\begin{array}{llll}\text { SON 1995 } & \text { KBM } & 3.0 & +0.68(+0.42) \\ \text { SON 2007 } & \text { ARM } & 3.3 & +1.33(+1.40) \\ \text { SON 2018 } & \text { ARI } & 3.2 & +1.63(+1.36)\end{array}$

$-27.11(-2.99)$

10.7

$+0.06(+0.78)$

$-15.2(-3.47)$

52.7

$+0.31(+3.07)$

$-2.76(-1.60)$

32.3

Table 2. Extreme seasons in DJF, JJA, MAM and SON, including the affected sub-regions and respective Mahalanobis distance $\left(d_{M}\right.$, see Sect. 2.3), the seasonal-mean anomalies of $T_{2 m}, P$ and $E_{S}$ (standardized seasonal-mean anomalies in brackets) and total affected area.

\subsection{Arctic extreme and anomalous seasons}

310 Using a threshold for the anomaly magnitude ( $d_{M} \geq 3$, see Sect. 2.3), seasons that appear as clear outliers in their respective PCA biplot are defined as extreme seasons, whereas seasons located at the edges of the point cloud formed by all seasons are characterized as anomalous seasons $\left(3>d_{M} \geq 2\right)$. The two thresholds are chosen pragmatically to distinguish seasons with different anomaly magnitudes and to classify the season with the largest anomaly magnitude as "extreme season". The term extreme season is appropriate as their return period corresponds to approximately 40 years in a given region. With our thresholds we find 2 extreme seasons in DJF, JJA and MAM, respectively, and 3 extreme seasons in SON (Table 2). The number of sub-regions where one particular season is identified as extreme varies between one and three, however the varying size of the sub-regions and thus significant differences in the extent of the affected area have to be considered. Further we identify on average 3.3 anomalous seasons per sub-region in DJF, 5 anomalous seasons per sub-region in JJA, 4.7 anomalous seasons per 
https://doi.org/10.5194/wcd-2021-18

Preprint. Discussion started: 13 April 2021

Weather and

(c) Author(s) 2021. CC BY 4.0 License.

Climate Dynamics

(c) (1)

sub-region in MAM and 4.4 anomalous seasons per sub-region in SON (see supplementary Tables S1-S4).
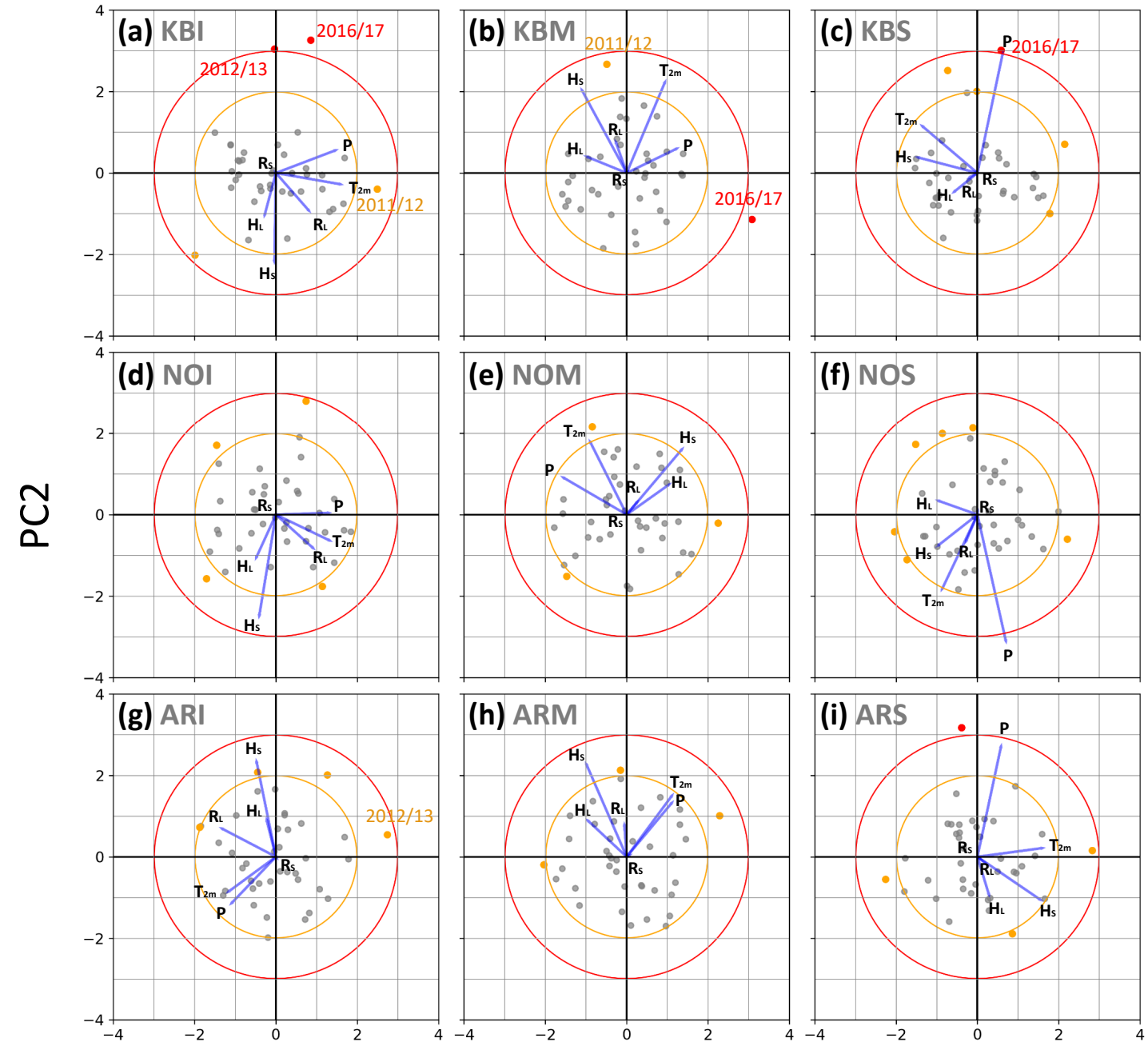

PC1

Figure 7. PCA biplot for all sub-regions in DJF with PC1 and PC2 along the x- and y-axis, respectively. Every season is represented by a grey dot, red and orange dots show extreme and anomalous seasons, respectively. Blue lines represent the coefficients of the precursor variables. Red and orange circles represent $d_{M}=3$ and $d_{M}=2$, the thresholds used for extreme and anomalous seasons, respectively. Selected case study seasons are labeled. 

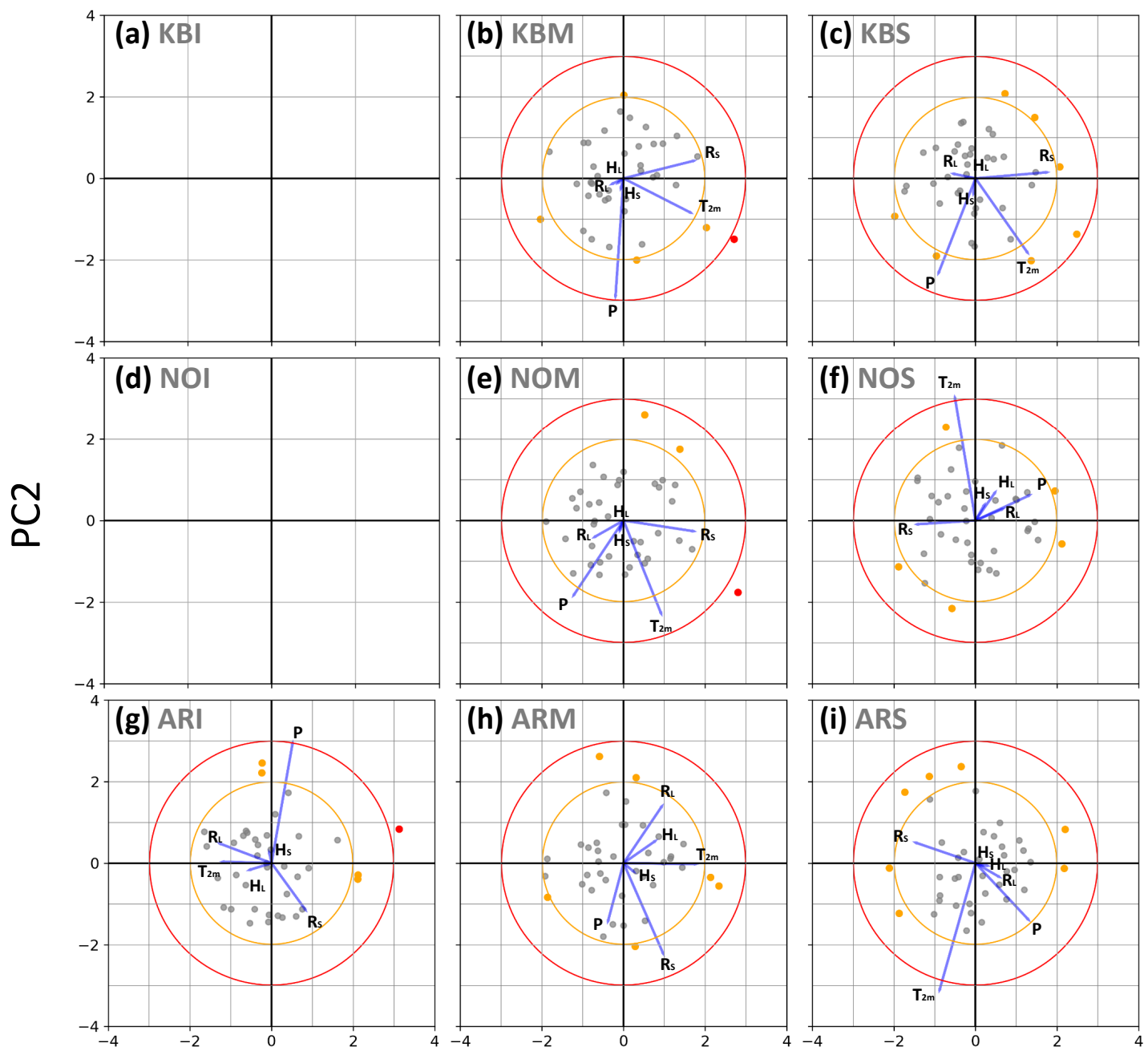

PC1

Figure 8. As Fig. 7 but for JJA. No biplots are shown for the sub-regions KBI and NOI, because they fall below the minimum size threshold of $10^{5} \mathrm{~km}^{2}$ in summer.

It is now interesting to briefly reconsider Figs. 5 and 6 and focus on the extreme and anomalous seasons, shown by red and orange dots, respectively, in comparison to all seasons in the study period. By design, extreme seasons have very large anomalies for at least one parameter, for example the strong positive and nearly continuous $\overline{P^{*}}$ in the extreme winter in KBM (Fig. 5h) or the negative $\overline{E_{S}{ }^{*}}$ in both extreme winters in KBI (Fig. 5j). In summer, all extreme seasons are characterized by a strong $\overline{T_{2 m}{ }^{*}}$ outlier (Fig. 6a, c, d), which coincides with an equally strong $\overline{E_{S}{ }^{*}}$ outlier in ARI (Fig. 6i). Similarly, most anomalous seasons also show outliers or anomalies near the edge of the point cloud for at least one parameter. However, some anomalous 
seasons don't show very strong anomalies in one particular parameter, which implies that for these seasons it is the combination of several parameters that makes them anomalous. In a given region, several extreme or anomalous seasons can have similar seasonal anomalies, for instance both extreme winters in KBI (Fig. 5b, f, j) and two anomalous and one extreme summers in ARI (Fig. 6a, e, i), indicating similar characteristics and most likely also underlying processes causing the anomalous nature of these seasons. However, in other regions with multiple anomalous seasons, they show a similar behavior in one but a contrasting behavior in another variable. For example, the anomalous winters in KBM both have a positive $\overline{T_{2 m}{ }^{*}}$ but different signs in their respective $\overline{E_{S}{ }^{*}}$ (Fig. 5d and 1). We thus expect different processes to be responsible for these seasons to be anomalous.

Based on the results of the PCA analysis and Fig. 5, two extreme and one anomalous winters are chosen for detailed case studies to better understand their seasonal substructure as well as the underlying processes. The selected seasons are the winters 2011/12 and 2016/17 in the Kara-Barents Seas and the winter 2012/13 in ARI. A third extreme winter in region ARS is disregarded, as ARS is only a very small region that consists of two remote fragments and thus the meaningful analysis of the involved processes would be less straightforward. Furthermore this selection allows to, on one hand, contrast two seasons in the same geographical region, and on the other hand also point out differences in terms of the underlying processes in a region at the edge of the Arctic and in the High Arctic.

\section{Case Studies}

\subsection{DJF 2011/12}

The winter of 2011/12 is classified as an anomalous season in KBI and KBM. In both sub-regions, this winter shows the largest positive $\overline{T_{2 m}{ }^{*}}$ during the 39-year study period (Fig. 7b and d). The time series in Fig. 9a shows that the daily-mean surface temperature is continuously above the climatology (consistent with the fact that the dots in Fig. $5 \mathrm{~b}$ and $\mathrm{d}$ are on the diagonal). In KBI, $\overline{T_{2 m}{ }^{*}}$ is the main contributor to this season's anomaly magnitude, supported by positive $\overline{P^{*}}$ and $\overline{R_{L}{ }^{*}}$ (Figs. 5b and f, and 7a). In KBM, positive $\overline{T_{2 m}{ }^{*}}$ and $\overline{H_{S}{ }^{*}}$ mainly determine the exceptional character of this winter (Figs. 5d and 7b), which also leads to one of the most positive $\overline{E_{S}{ }^{*}}$ compared to all winters in the study period (Fig. 51).

In DJF 2011/12, $\overline{T_{2 m}{ }^{*}}$ is about $+6.6 \mathrm{~K}$ in $\mathbf{K B I}$ and $+4.7 \mathrm{~K}$ in $\mathbf{K B M}$. In the whole region, during December, values are continuously around $+6 \mathrm{~K}$ above climatology, before approaching more normal levels at the beginning of January (Fig. 9a). The largest $T_{2 m}{ }^{*}$ values are reached in February. The SIC anomaly shows an opposite behavior and is continuously negative, reaching values close to climatology only at the beginning of the season and during the period with reduced $T_{2 m}{ }^{*}$ in January (Fig. 9c). Similarly to the other variables, we here calculate the SIC anomaly using a transient climatology, as this effectively removes non-linear SIC trends in the Kara-Barents Seas (see Fig. S1c and d in the supplement). Daily-mean $E_{S}$ values are strongly correlated with daily-mean $T_{2 m}$, resulting in mostly positive $E_{S}{ }^{*}$ during the particularly warm episodes and shorter periods of negative $E_{S}{ }^{*}$ when $T_{2 m}{ }^{*}$ is reduced (Fig. $9 \mathrm{~b}$ ). The positive $\overline{E_{S}{ }^{*}}$ is mainly due to a strongly positive $\overline{H_{S}{ }^{*}}$, i.e., strongly reduced heat fluxes into the atmosphere, favored by the warm surface temperatures and comparatively few CAOs (see 
next paragraph). During the period with the largest $T_{2 m}{ }^{*}$ in February, when the surface air temperatures exceed $0{ }^{\circ} \mathrm{C}$ at several grid points on multiple days, even positive $H_{S}$ values occur over the open ocean (not shown). Daily $P$ values show only small deviations from climatology, except for the first five days of the season and in the beginning of February (Fig. 9d).

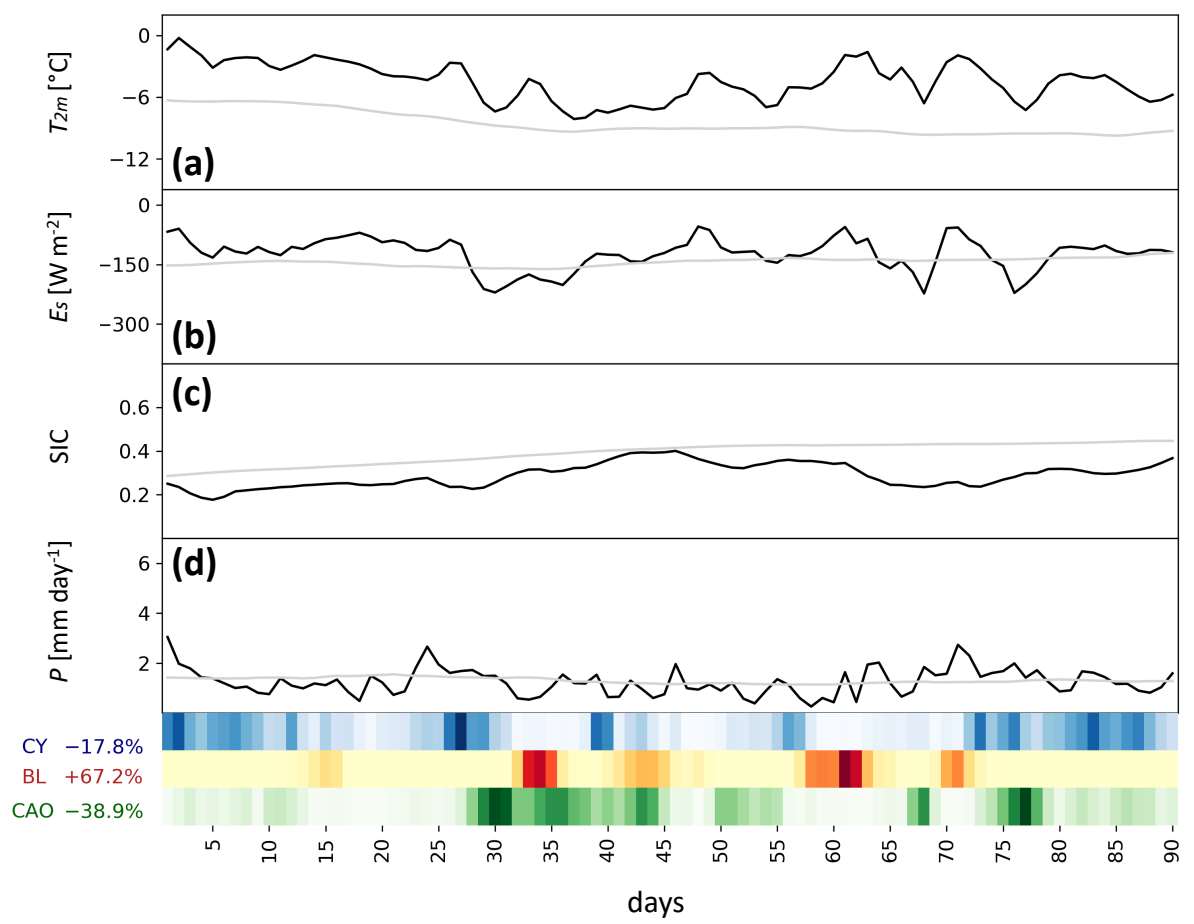

Figure 9. Time series of daily-mean (a) $T_{2 m}$ (in ${ }^{\circ} \mathrm{C}$ ), (b) $E_{S}$ (in $\mathrm{W} \mathrm{m}^{-2}$ ), (c) SIC and (d) $P$ (in mm day ${ }^{-1}$ ) averaged in the region of the Kara-Barents Seas (KBI, KBM, and KBS) in DJF 2011/12 (black lines). The transient climatology is shown by grey lines. Blue, orange, and green heatmaps at the bottom of the figure show the daily-mean coverage of the region by cyclones, blocks, and CAOs, respectively (the darker the color the higher the coverage). Relative frequency anomalies of the three weather systems are given in percentages. The horizontal axis indicates days since the start of the season with day 1 corresponding to 01 December.

It is now interesting to compare the time series of the basic variables with the occurrence of specific weather systems. The colored heatmaps at the bottom of Fig. 9 provide information about the occurrence of cyclones, blocks and CAOs in the Kara-Barents Seas. Here, the color intensity is representative for the percentage of the sub-regions' area which overlaps with a cyclone, blocking or CAO mask on a daily basis. The repeated passage of cyclones (Fig. 9, blue heatmap) originating from the Nordic Seas (not shown) ensures the continuous transport of warm and moist air masses into the Kara-Barents Seas throughout several periods, mostly during December and February. Yet, in the wintertime average, cyclone frequency in this region was slightly below climatology. In contrast, CAO frequency (Fig. 9, green heatmap) was strongly reduced while blocking frequency 
https://doi.org/10.5194/wcd-2021-18

Preprint. Discussion started: 13 April 2021

(C) Author(s) 2021. CC BY 4.0 License.
Weather and

Climate Dynamics

Discussions

was substantially increased (Fig. 9, red heatmap) in this season. CAOs, which often occur after the passage of a cyclone, as can be seen for example around days 30, 43 and 77, usually lead to a strong decrease in $T_{2 m}$ and $E_{S}$ (associated with intense surface fluxes). Therefore, the relative lack of CAOs in this winter favors the persistence of above average $T_{2 m}$. Several blocking episodes around days 34, 61 and 71 are associated with notable peaks of $T_{2 m}$ and $E_{S}$. Animations S1-3 in the supplementary material show daily synoptic plots for each of the discussed case studies and further illustrate the interplay of the synoptic systems and the occurrence of the anomalies in the considered surface parameters.

This season's large anomaly magnitude in sub-regions KBI and KBM was mainly determined by its exceptionally positive $\overline{T_{2 m}{ }^{*}}$ and the resulting positive $\overline{H_{S}{ }^{*}}$, favored by unusually frequent blocking events and the reduced frequency of CAOs throughout the season.

\subsection{DJF 2016/17}

The winter 2016/17 is classified as extreme in all sub-regions of the Kara-Barents Seas. The PCA biplot shows that in KBI and KBM the anomaly magnitude of this winter is mainly determined by negative surface flux anomalies, especially of $H_{S}$ (Fig. 7a and b). In KBS, a positive $\overline{P^{*}}$ is the strongest contributor to the anomaly magnitude (Fig. 7c) and in KBM this winter occurs with a strong positive $\overline{P^{*}}$ outlier (Fig. 5h). In fact, it is the winter with the most precipitation in the Kara-Barents Seas during the study period. Further, in KBI and KBM, a strongly negative $\overline{E_{S}{ }^{*}}$ occurs as a clear outlier with respect to other winters (Fig. 5j and 1). Finally, $\overline{T_{2 m}{ }^{*}}$ shows a positive anomaly in KBM and KBS, which, however, is not exceptional (Fig. 5d). 


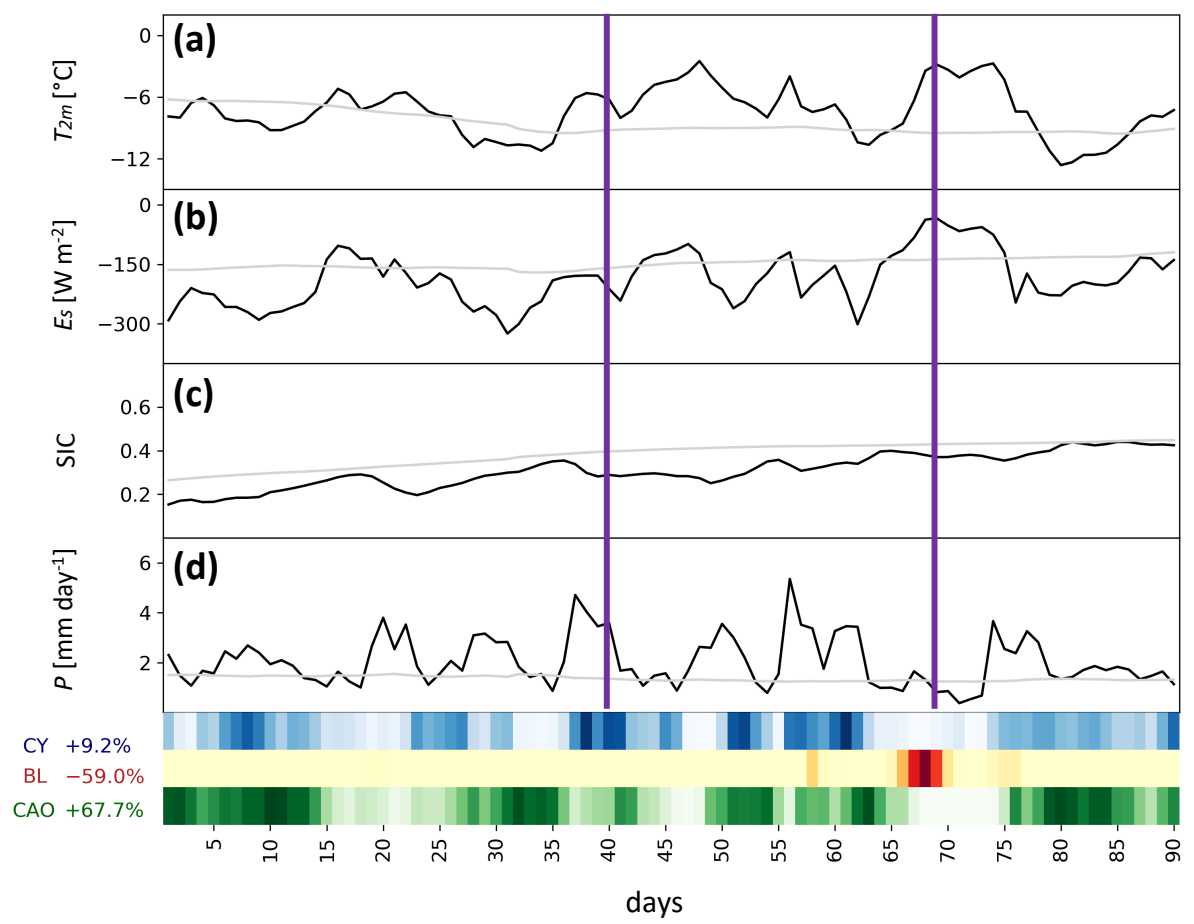

Figure 10. Time series of daily-mean (a) $T_{2 m}$ (in ${ }^{\circ} \mathrm{C}$ ), (b) $E_{S}$ (in $\mathrm{W} \mathrm{m}^{-2}$ ), (c) SIC and (d) $P$ (in mm day ${ }^{-1}$ ) averaged in the region of the Kara-Barents Seas (KBI, KBM, and KBS) in DJF 2016/17 (black lines). The transient climatology is shown by grey lines. Purple vertical lines indicate the two time steps shown in Fig. 11, 09 January 2017 and 07 February 2017, respectively. Blue, orange, and green heatmaps at the bottom of the figure show the daily-mean coverage of the region by cyclones, blocks, and CAOs, respectively (the darker the color the higher the coverage). Relative frequency anomalies of the three weather systems are given in percentages. The horizontal axis indicates days since the start of the season with day 1 corresponding to 01 December.

Several episodic precipitation events result in the strongly positive $\overline{P^{*}}$ which often can be linked to the passage of a cyclone (Fig. 10d, blue heatmap). Only very few episodes show $P^{*}$ values below climatology, e.g. at the beginning of February when the occurrence of a block causes dry conditions (Fig. 10d, red heatmap). The positive $\overline{T_{2 m}{ }^{*}}$ results from several episodic warm events with a duration of $\sim 5-10$ days (Fig. 10a), each deviating more than $+5 \mathrm{~K}$ from climatology. There are, however, also several periods that are notably colder than climatology, thus implying a small seasonal-mean anomaly. This periods typically are characterized by a CAO (Fig. 10, green heatmap). A negative SIC anomaly occurs throughout the season (Fig. 10b), which is especially pronounced in KBM (not shown), with strong decreases in SIC following warm and wet episodes linked to the passage of cyclones (Fig. 10, blue heatmap). During these episodes, which occur for example around days 21, 37 and 57, the wind field associated with the cyclone affects the sea ice transport and pushes the sea ice edge further north, momentarily reducing the sea ice coverage mainly in the region KBM. In the supplementary Fig. S4 we show an example, using PIOMAS 
sea ice data (Schweiger et al., 2011), of how the passage of several cyclones between 17 December and 24 December affects the sea ice transport in the Kara-Barents Seas. The most prominent anomaly during this winter however is the strongly negative $\overline{E_{S}{ }^{*}}$ (Fig. 10b), particularly pronounced in KBI and KBM, mainly resulting from negative $\overline{H_{L}{ }^{*}}$ and $\overline{H_{S}{ }^{*}}$. This negative $E_{S}$ anomaly is closely linked to SIC anomalies and episodic cold periods. Specifically, the reduction in sea ice coverage and, thus, increased area of open ocean leads to more intense upward surface heat fluxes. A slightly positive tendency of $E_{S}$ is found for episodes where SIC returns to climatological values, for example in February 2017 (Fig. 10b and c). In addition, the most negative values of $E_{S}$ occur during cold periods related to marine CAOs (Fig. 10a and b).

Analysing the weather systems during this winter reveals that the single warm events are driven by different synoptic processes. Figure 11 exemplarily shows two characteristic but different synoptic circulation patterns associated with anomalously warm conditions on 09 January 2017 (Fig. 11a) and on 07 February 2017 (Fig. 11b). In January 2017, a sequence of multiple cyclones continuously transport warm air from the southwest towards the Kara-Barents Seas (Figs. 10, blue heat map, 11a and supplementary animation S2). Figure 11a shows a typical situation where a cyclone from the Nordic Seas propagated into the Kara-Barents Seas region, leading to anomalously warm conditions in its warm sector and precipitation along its cold front. Since the cyclones become nearly stationary and a large part of their cold sector is often located outside of the region in the Greenland Sea or towards the High Arctic, they cause a net warming in the region of the Kara-Barents Seas as well as persistent precipitation during their passage (Fig. 10a and d). Figure 11b shows the persistent large-scale situation during the warming episode in February 2017, when a stationary block over northern Scandinavia in combination with a strong cyclone to the South of Greenland leads to anomalously warm conditions in its northern periphery (Figs. 10, red heatmap, 11b and supplementary animation S2). Next to the enhanced poleward transport of mid-latitude air masses which is favored by this pattern, subsidence-induced adiabatic warming additionally causes high surface temperatures for the duration of the block (cf. Papritz, 2020). At the same time, the presence of the block suppresses precipitation in the region, resulting in one of the driest periods of the season (Fig. 10d).

In January, daily-mean $E_{S}$ values correlate well with daily-mean $T_{2 m}$ values with the most negative $E_{S}$ values on the colder days. Despite of this, $E_{S}$ shows a negative seasonal-mean anomaly, as $\mathrm{SIC}^{*}$ values are strongly negative and frequent CAO events (Fig. 10, green heatmap) enhance surface fluxes into the atmosphere. In February, when SIC levels show only small negative anomalies and thus anomalous heat fluxes into the atmosphere are smaller, strong positive $H_{S}{ }^{*}, H_{L}{ }^{*}$ and $R_{L}{ }^{*}$ during the blocking event lead to the largest positive $E_{S}{ }^{*}$ values throughout the winter, followed again by a period with frequent CAOs and strongly negative $E_{S}{ }^{*}$ values. 

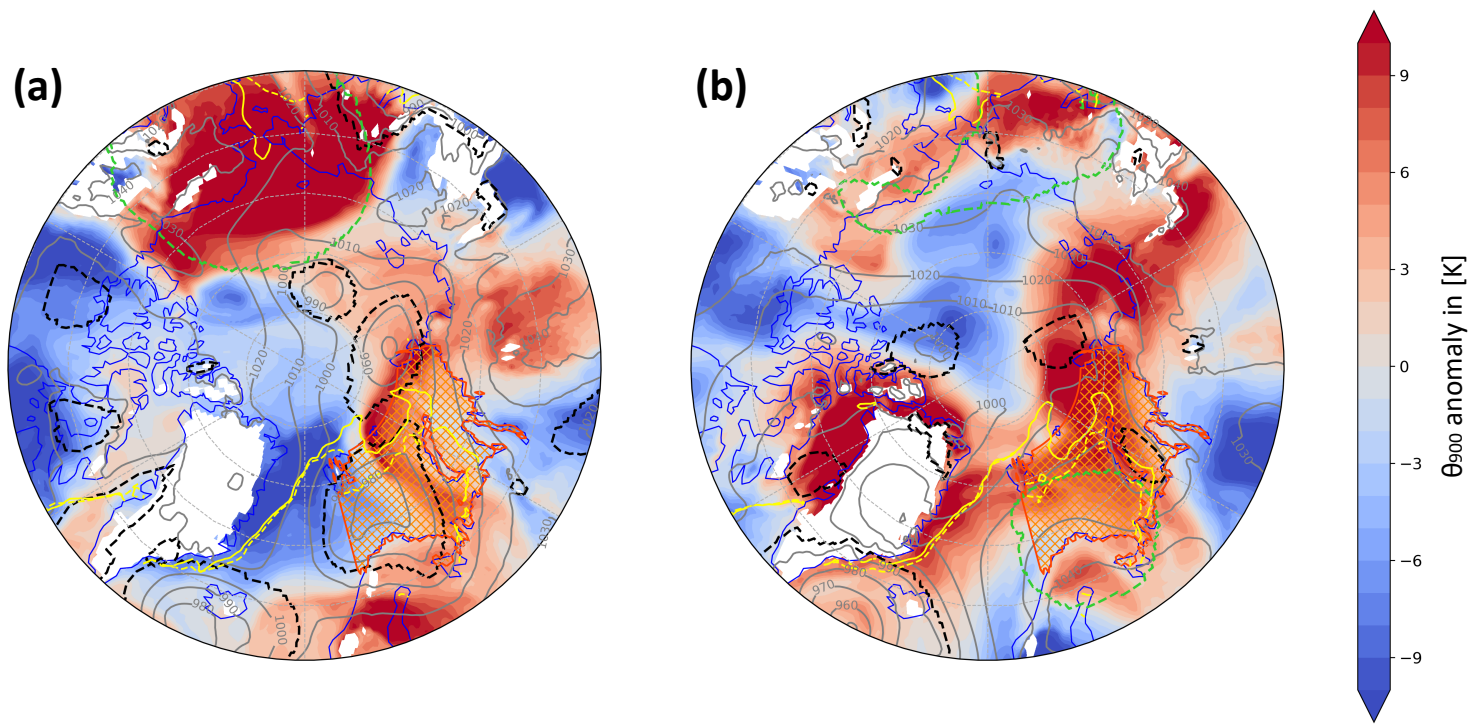

Figure 11. Synoptic situation on (a) 09 January 2017 and (b) 07 February 2017. Daily anomaly of potential temperature at $900 \mathrm{hPa}\left(\theta_{900}\right.$; K, color). Instantaneous sea-level pressure (SLP, grey contour, in intervals of $10 \mathrm{hPa}$ ), sea ice edge (SIC $=0.5$, solid yellow line), climatological sea ice edge $\left(\mathrm{SIC}_{\text {clim }}=0.5\right.$, dashed yellow line), cyclone mask (dashed black contour) and blocking mask (dashed green contour) at $00 \mathrm{UTC}$ on the considered days. The region of the Kara-Barents Seas is marked by orange hatching.

Besides synoptic processes, also preconditioning potentially plays an important role for the occurrence of an extreme season, as we aim to discuss now. From Fig. 10c, it is obvious that SIC in the Kara-Barents Seas was already exceptionally low at the start of the winter season, in fact, the sea ice extent on 01 December was the lowest at this date for the entire study period. At the same time, the sea surface temperature (SST) shows a significantly positive anomaly of about $+1 \mathrm{~K}$ on average, which favors a delayed freeze-up in the region and at the same time also more intense upward sensible and latent heat fluxes. These initial surface conditions provide an important precondition for the strongly negative $\overline{E_{S}{ }^{*}}$, which itself is decisive for the anomaly magnitude of this winter. Analysing SIC and SST anomalies in the Kara-Barents Seas during the previous seasons in 2016 shows that they developed since the previous winter (SIC) or spring 2016 (SST, see Fig. 13b). At the end of 2015, an extreme warm event (e.g. Boisvert et al., 2016; Binder et al., 2017) led to a significant thinning of the sea ice in the Kara-Barents Seas, causing an early start of the melt season in 2016 and subsequently increased SST values in MAM, coinciding with a positive

$\overline{T_{2 m}{ }^{*}}$ in the same region. The summer of 2016 does occur as an extreme season in sub-regions KBM and NOM (Fig. $8 \mathrm{~b}$ and e) and as an anomalous season in KBS (Fig. 8c), mainly due to a strong $\overline{T_{2 m}{ }^{*}}$ of on average $+1.4 \mathrm{~K}$ in the Kara-Barents Seas, which was facilitated by a reduction in total cloud cover and thus strongly enhanced $R_{S}$. Together with the already existing positive SST anomaly this extremely warm summer led to record low SIC and ice-free conditions in the Barents Sea from July to September (Petty et al., 2018). Strong blocking over large parts of the Arctic during autumn 2016 caused positive surface 
https://doi.org/10.5194/wcd-2021-18

Preprint. Discussion started: 13 April 2021

(c) Author(s) 2021. CC BY 4.0 License.

(c) (1)

Weather and

Climate Dynamics

Discussions

445 temperature anomalies across the whole Arctic region (Tyrlis et al., 2019) as well as strong positive $E_{S}$ anomalies, favoring the persistence of the negative SIC and positive SST anomalies (Blunden and Arndt, 2017) until the beginning of DJF 2016/17.

In summary, the winter 2016/17 was extreme in the Kara and Barents Seas due to a combination of preconditioning and favourable synoptic conditions. Specifically, a combination of strongly positive $\overline{\mathrm{SST}^{*}}$ and negative $\overline{\mathrm{SIC}^{*}}$ at the beginning of the season, and a relatively large number of CAO events throughout the season, resulted in strongly negative surface heat flux anomalies. Furthermore, an enhanced frequency of cyclones transporting warm and humid air masses into the region lead to a strongly enhanced $\overline{P^{*}}$.

\subsection{Comparison DJF 2011/12 and DJF 2016/17}

Comparing both anomalous winters in the Kara-Barents Seas, it becomes already evident from the PCA biplots (Fig. 7a and b)

that the processes leading to their respective anomaly magnitude are fundamentally different, as the vectors pointing to the two seasons in the biplot are nearly orthogonal. The winter of 2011/12 is dominated by a continuous positive $T_{2 m}$ anomaly favored by a reduced frequency of CAO events, whereas in DJF 2016/17 the negative heat flux anomalies and exceptionally positive $\overline{P^{*}}$, enhanced by strongly reduced sea ice cover are most important. 
https://doi.org/10.5194/wcd-2021-18

Preprint. Discussion started: 13 April 2021

(C) Author(s) 2021. CC BY 4.0 License.

\section{(c) (i)}

Weather and

Climate Dynamics

Discussions
L. (b) DJF 2016/17

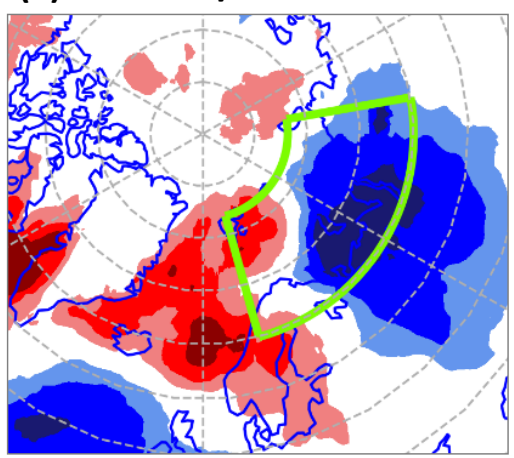

(c) DJF 2011/12

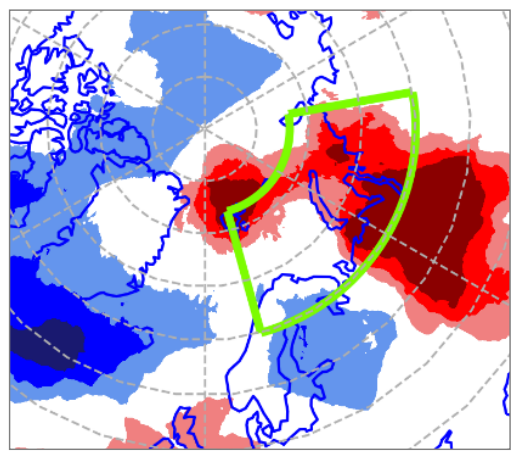

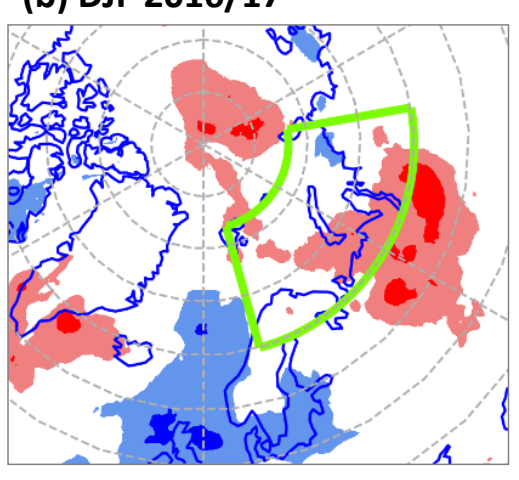

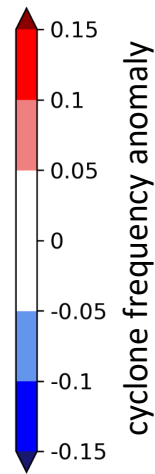

(d) DJF 2016/17

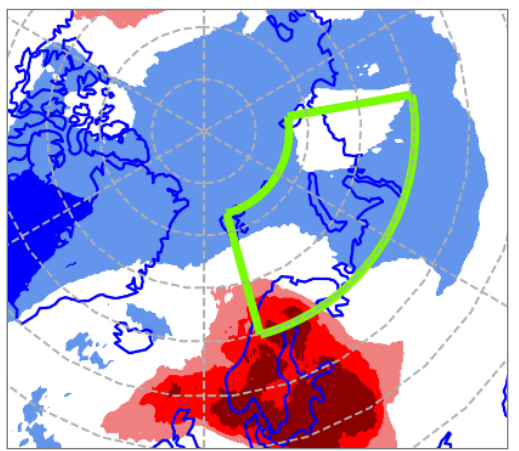

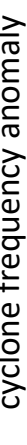

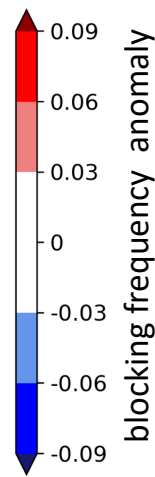

Figure 12. Seasonal-mean cyclone frequency (a, b) and blocking frequency (c, d) anomalies for DJF 2011/12 (a, c) and DJF 2016/17 (b, d). Region of the Kara-Barents Seas is marked with green contour.

The synoptic activity differs between these seasons. In DJF 2011/12, cyclone frequency was strongly enhanced over the Nordic Seas concomitant with a reduction in the Kara-Barents Seas (Fig. 12a). This favored the frequent advection of warm air masses into the Barents Sea. Since enhanced cyclone activity was restricted to the Nordic Seas where several cyclones slowed down and got stationary (see supplementary animation S1), also the frequency of cold air outbreaks, which preferentially occur in the cyclone's cold sectors, was reduced in the Kara-Barents Seas. In addition, recurrent blocks over the Ural mountains (Fig. 12c) contributed to above normal surface temperatures. In DJF 2016/17, in contrast, cyclone activity was close to climatology (Fig. 12b), but instead blocking frequency over Scandinavia was strongly enhanced (Fig. 12d). Subsidence-induced warming and long-range transport of warm air masses contributed to several warm episodes. However, an enhanced frequency of CAOs, facilitated by the frequent passage of cyclones combined with reduced SIC and warm ocean temperatures, limited $\overline{T_{2 m}{ }^{*}}$ but contributed to a strongly negative $\overline{E_{S}{ }^{*}}$. Thus, the patterns of synoptic activity were partly reversed between the two 
https://doi.org/10.5194/wcd-2021-18

Preprint. Discussion started: 13 April 2021

(c) Author(s) 2021. CC BY 4.0 License.

Weather and

Climate Dynamics

(c) (i)

seasons, yet they contributed substantially to their anomalous nature.
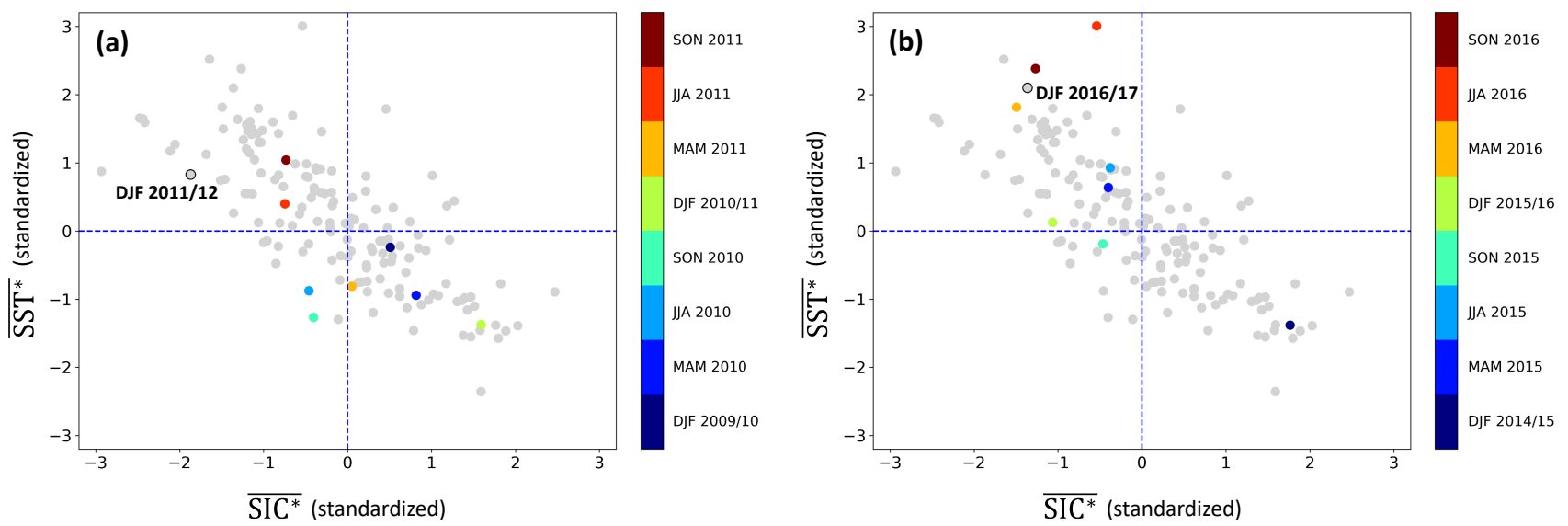

Figure 13. Standardized seasonal-mean anomalies of SIC ( $\overline{\mathrm{SIC}^{*}}$; along $\mathrm{x}$-axis $)$ and SST $\left(\overline{\mathrm{SST}^{*}}\right.$; in K, along y-axis $)$ in the Kara-Barents Seas for the entire study period (grey dots) including all seasons. Colored dots highlight the eight seasons preceding (a) the anomalous winter 2011/12 and (b) the extreme winter 2016/17.

In addition to the synoptic activity, we found the influence of preconditioning in SIC and SST values to be of great importance for DJF 2016/17. Figure 13b shows persistent negative $\overline{\mathrm{SIC}^{*}}$ and positive $\overline{\mathrm{SST}^{*}}$ throughout the preceding 1.5 years. Comparing the initial conditions for the winter of 2011/12, the influence of the previous seasons seems to be minor, as SIC and SST values are close to normal at the beginning of the winter and seasonal-mean anomalies in spring and summer 2011 show no significant negative and positive anomalies, respectively (Fig. 13a).

\subsection{DJF 2012/13}

In the region of the High Arctic, the winter of 2012/13 is classified as strongly anomalous in ARI mainly due to its negative $\overline{T_{2 m}{ }^{*}}$ and $\overline{P^{*}}$ (Fig. 7g), making it one of the coldest and driest winters in this sub-region (Fig. 5a and e). A negative $\overline{R_{L}{ }^{*}}$, i.e., less net longwave radiation, resulting in an overall strongly negative $\overline{E_{S}{ }^{*}}$ contributes additionally to the anomaly magnitude of this winter (Fig. 5i). Figure 14a shows that the $T_{2 m}$ anomaly mainly results from deviations up to $-8 \mathrm{~K}$ from the climatology during the second half of the season, which is quite a substantial anomaly considering the size of the spatially averaged area, whereas the first half of the season is close to climatology. From mid-January on, $E_{S}$ values are also consistently below average and little to no precipitation occurs until the end of the winter (Fig. 14b and e). It is evident that only the second half of the season features exceptional conditions, indicating that anomalies do not have to persist throughout a whole season to make it anomalous. 


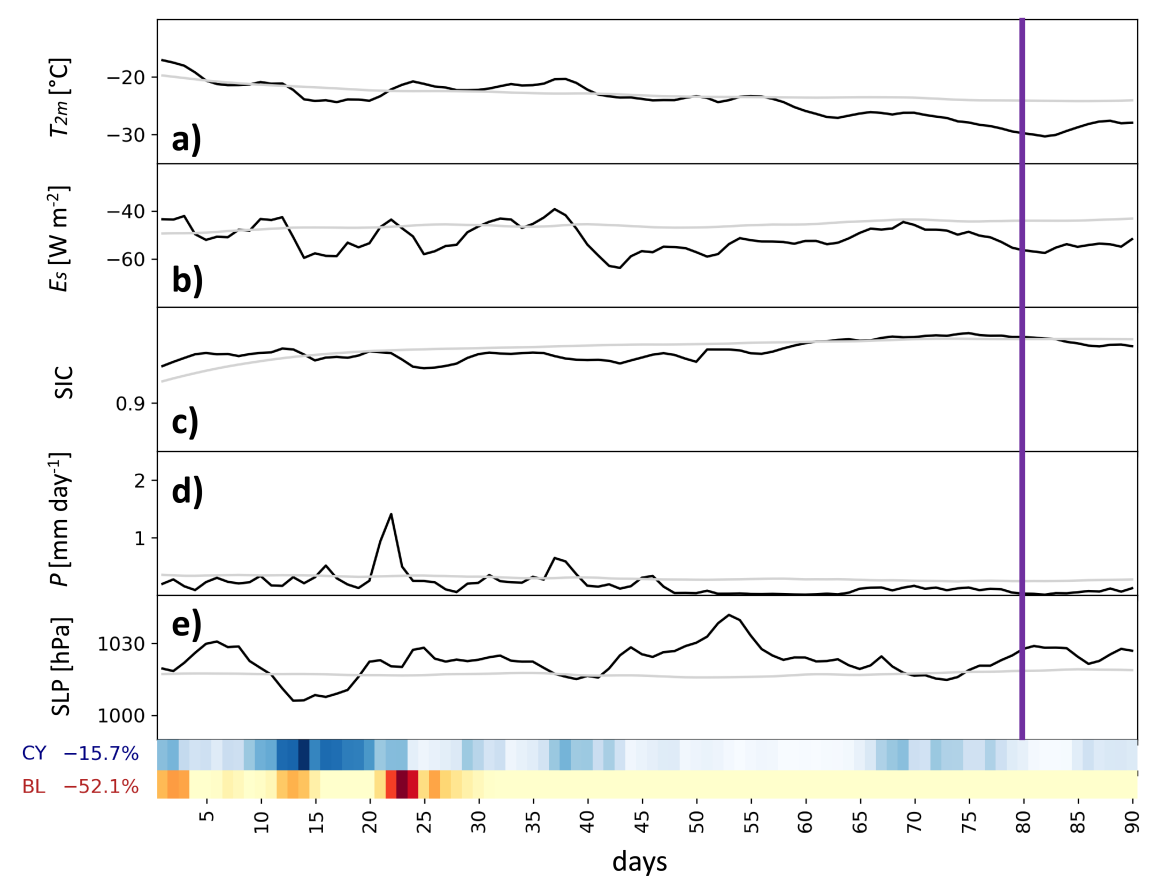

Figure 14. Time series of daily-mean (a) $T_{2 m}$ (in ${ }^{\circ} \mathrm{C}$ ), (b) $E_{S}$ (in $\mathrm{W} \mathrm{m}^{-2}$ ), (c) SIC and (d) $P$ (in mm day ${ }^{-1}$ ) averaged in the sub-region ARI in DJF 2012/13 (black lines). The transient climatology is shown by grey lines. Purple vertical line indicates the time step shown in Fig. 15, 18 February 2013. Blue, orange, and green heatmaps at the bottom of the figure show the daily-mean coverage of the region by cyclones, blocks, and CAOs, respectively (the darker the color the higher the coverage). Relative frequency anomalies of the three weather systems are given in percentages. The horizontal axis indicates days since the start of the season with day 1 corresponding to 01 December.

The anomalies during the second half of the season coincide with a decrease of synoptic activity over the High Arctic. Specifically, the relative cyclone and blocking frequency anomalies in ARI are slightly and strongly reduced, respectively, especially in the second half of the season. In December, several cyclones and blocks affect the prevalent conditions in the High Arctic (Fig. 14, blue and red heatmaps and supplementary animation S3). Between 20 December and 25 December, a strong intrusion of warm and moist air facilitated by adjacent blocking and cyclone systems in the Bering Sea causes a strong precipitation event, coinciding with increasing surface mean temperatures and a local decline in sea ice coverage (Fig. 14a, c, d). At the same time, a displacement of the polar vortex occurs, which subsequently leads to a splitting of the polar vortex and a sudden stratospheric warming event at the beginning of January 2013 (Coy and Pawson, 2015; Nath et al., 2016). As the region of the High Arctic is positioned beneath the saddle point of the resulting two cyclonic vortices in the stratosphere, relatively calm conditions lead to the development of a high pressure system in the Laptev Sea, which evolves into a strong and persistent polar high during January (Fig. 14e). Persistent radiative cooling induces a first drop in $T_{2 m}$ at the end of January (Fig. 14a). In February, the calm conditions in the High Arctic remain and prolong the isolation of the cold and dry air in this region. With 
the increasing dryness of the air, persistent longwave radiative cooling results in a dome of very cold air, as reflected by the air mass below the $275 \mathrm{~K}$ isentrope, covering nearly the whole High Arctic region between 17 February and 21 February (Fig. 15 and supplementary animation S3). The conditions in February cause one of the strongest negative monthly $T_{2 m}$ anomalies in this region.

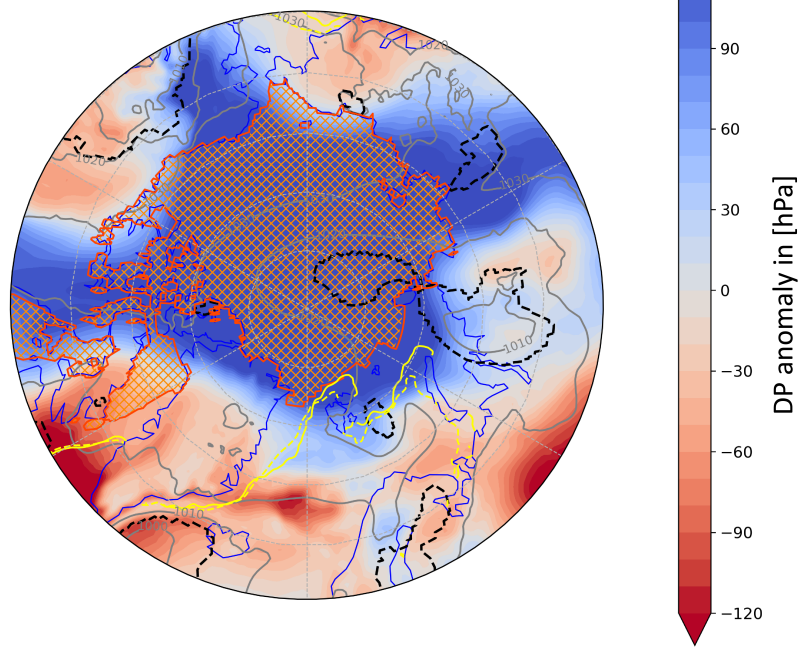

Figure 15. Synoptic situation on 18 February 2013. Daily anomaly of the cold air mass DP, defined as the mass below the $275 \mathrm{~K}$ isentropic surface (in $\mathrm{hPa}$, color). Instantaneous sea-level pressure (SLP, grey contour, in intervals of $10 \mathrm{hPa}$ ), sea ice edge (SIC $=0.5$, solid yellow line), climatological sea ice edge $\left(\mathrm{SIC}_{\mathrm{clim}}=0.5\right.$, dashed yellow line), cyclone mask (dashed black contour) and blocking mask (dashed green contour) at 00 UTC. Sub-region ARI is marked by orange hatching.

Comparing winter 2012/13 in ARI with the two anomalous winters in the Kara-Barents Seas reveals fundamentally different characteristics, resulting mainly from the regionally varying synoptic activity but also the prevalent surface conditions. While preconditioning does not play an important role in the High Arctic, which is mainly covered by sea ice, the long-term development of SIC and SST anomalies in areas with varying SIC can significantly influence the initial conditions of winters in the Kara-Barents Seas. Each of the three seasons has its own substructure and different combination of anomalies resulting in the respective anomaly magnitude. Besides the rather straightforward "continuous anomaly in one parameter" as it is the case for DJF 2011/12, we show that, with our approach to define extreme and anomalous seasons based on a multi-variate anomaly magnitude, there are many different pathways for such a season to develop. In DJF 2012/13, several weeks of consistent extreme conditions resulted in a whole anomalous season, although the first half of the winter was relatively normal. And in 2016/17, it was not only extraordinary atmospheric conditions but also the preconditioning by an anomalous evolution of the surface conditions during the previous months that led to an extreme Arctic winter. 
https://doi.org/10.5194/wcd-2021-18

Preprint. Discussion started: 13 April 2021

(c) Author(s) 2021. CC BY 4.0 License.

(c) (i)

Weather and

Climate Dynamics

Discussions

\section{Discussion and conclusions}

In this study, Arctic winters (DJF) and summers (JJA) have been characterized based on seasonal anomalies of surface parameters including temperature, radiation, heat fluxes and precipitation for distinct regions considering varying surface conditions. In winter, strong spatial differences can be observed dependent on the prevailing surface conditions (i.e., open ocean vs. sea ice), especially in terms of the surface energy balance components $\left(E_{S}\right)$. Regions with a climatological sea ice concentration of above $90 \%$ show only small $E_{S}$ variability mainly determined by changes in the net surface thermal radiation, as solar radiation and air-sea interactions are strongly reduced, particularly in the high latitudes. In contrast, areas with predominantly open water surface show a large seasonal variability in the surface energy balance primarily driven by fluctuations in the surface heat fluxes. Temperature anomalies do show a distinct spatial variability as well, featuring relatively large fluctuations in sea ice covered areas in the Kara-Barents and Nordic Seas and reduced variability over the open ocean. The Nordic Seas are further characterized by an increased precipitation variability compared to the Kara-Barents Seas and the High Arctic, whereby the latter shows smaller variability for all analyzed parameters.

Reduced surface radiation and temperature gradients as well as decreasing sea ice extent result in less heterogeneous conditions in the distinct sub-regions during summer. Only in the High Arctic, including areas of perennial sea ice, variability is clearly smaller compared to the other regions. As a consequence, the Arctic shows much more spatial variability during winter when meridional gradients in surface temperature and surface radiation are increased, leading to less homogeneous surface conditions and significant regional variability differences. Hence, it is reasonable to subdivide the Arctic into several regions considering these spatial differences to study anomalous Arctic winter seasons.

We further characterized Arctic seasons based on the seasonal substructure of surface temperature $\left(T_{2 m}\right)$, precipitation $(P)$ and $E_{S}$. Continuous seasonal anomalies, indicating constantly anomalous conditions of the same sign throughout a whole season, can be observed for $T_{2 m}$ and $E_{S}$ except for the open ocean, where strong surface heat flux variability prevents continuous $E_{S}$ anomalies. Distinct outlier seasons can be observed featuring exceptional seasonal-mean anomalies in one or several parameter(s).

To define and identify anomalous and extreme seasons objectively, we introduce a novel, multi-variate method. Using PCA, we define anomalous and extreme seasons by means of an anomaly magnitude based on the combination of seasonal anomalies of $T_{2 m}, P$, surface heat fluxes and surface net radiation. This multi-variate approach has the advantage over a univariate approach that it also allows to identify seasons that arise from an unusual combination of seasonal anomalies that taken alone are not particularly unusual. We analyze sub-regions with climatologically high, mixed or low sea ice cover separately, thus accounting for regional differences in the surface conditions, which have a strong impact on the variability of these parameters. With this approach, we find that our identified extreme and anomalous seasons result from various combinations of unusual 
https://doi.org/10.5194/wcd-2021-18

Preprint. Discussion started: 13 April 2021

(C) Author(s) 2021. CC BY 4.0 License.

seasonal anomalies.

Based on this definition of extreme seasons, we analyzed the atmospheric processes leading to three selected extreme and anomalous seasons by evaluating the relative importance of different synoptic features, namely cyclones, blocks and cold air outbreaks (CAO). This helps improving the understanding of the formation of such seasons and underlines the manifold processes that can cause a season to become particularly unusual. The results of our analysis for three different case studies can be summarized as follows:

1. Seasonal substructure: Extreme and anomalous Arctic winter seasons show a high variability in their substructure and the synoptic processes determining their anomaly magnitude. This magnitude can be due to a continuous seasonal anomaly in one parameter such as it is the case for the constantly positive temperature anomaly during the exceptionally warm winter 2011/12 in the Kara-Barents Seas. However, also the combination of several noticeable but not exceptional seasonal anomalies can result in a similarly large anomaly magnitude. Furthermore, extreme conditions do not need to persist during a whole season as we can see for the winter of 2012/13 in the High Arctic, where several weeks of persistent cold and dry conditions caused seasonal anomalies that are sufficiently large for the season to be identified as anomalous.

2. Atmospheric processes: Various synoptic processes can cause Arctic winters to become anomalous or extreme. An increase in cyclone frequency often leads to enhanced transport of warm and moist air into the respective region, which is particularly important for the formation of precipitation in the higher latitudes. Episodes of prevailing atmospheric blocking usually favor the persistence of positive surface temperature anomalies due to subsidence-induced adiabatic warming. Recurrent synoptic events such as cyclones, blocking and CAO episodes can strongly influence the entire season. Similarly, the absence of synoptic activity can be important for the development of extreme conditions as can be seen in the case of the High Arctic extreme winter 2012/13. Contrasting synoptic conditions can lead to extreme seasons in the Kara-Barents Seas, which, however, show very different characteristics. Further, the frequency of CAOs strongly influences surface temperature anomalies and changes in $E_{S}$ mainly due to the impact on air-sea interaction.

3. Surface preconditioning: Regions with varying sea ice coverage can experience preconditioning due to long-term anomalies in sea ice concentration (SIC) and sea surface temperature (SST), leading to anomalous initial conditions at the beginning of the season and thus influencing the sea ice formation and $E_{S}$ throughout the following winter. Large SIC and SST anomalies, which developed and persisted throughout the preceding 1.5 years, led to record-low SIC and above average SST in the Kara-Barents Seas at the beginning of the winter of 2016/17. Due to the increased amount of open water area, predominantly negative surface heat flux anomalies prevailed throughout the season, resulting in an exceptionally negative seasonal $E_{S}$ anomaly. This suggests that extreme and anomalous seasons in regions with a climatological sea ice concentration between $10 \%$ and $90 \%$ can be caused by such a preconditioning, whereas extreme and anomalous seasons in regions with continuous sea ice extent are mainly driven by atmospheric processes.

One of the main limitations of this study is the short time-period for which the ERA5 data is currently available. As our goal is to study anomalous seasons, the number of suitable cases is strongly limited. Future analysis of large ensemble simulations 
https://doi.org/10.5194/wcd-2021-18

Preprint. Discussion started: 13 April 2021

(C) Author(s) 2021. CC BY 4.0 License.
Weather and

Climate Dynamics

Discussions

of the CESM climate model will allow us to further statistically quantify and confirm the results of this study. The importance of long-term components such as the near-surface ocean processes leading to possible preconditioning of anomalous seasons have only been briefly considered in this study. Further analysis of anomalies in surface oceanic heat transport and its influence on sea ice formation and melt and sea surface temperatures will allow us to quantify the relative importance of short-term atmospheric and long-term oceanic forcing in driving the processes leading to Arctic extreme seasons.

Code and data availability. ERA5 data can be downloaded from the Copernicus Climate Data Store (https://cds.climate.copernicus.eu/). The PIOMAS data set can be obtained from the Polar Science Center web page (http://psc.apl.uw.edu/research/projects/arctic-sea-ice-volumeanomaly/data/). Scripts used to produce the analyses and figures in this study are available on request from the authors.

Author contributions. KH performed most of the analyses, produced all figures and wrote the initial draft of the manuscript. All authors contributed to the design of the study, the understanding and interpretation of the results and the writing of the paper.

Competing interests. The authors declare that they have no competing interests.

Acknowledgements. KH and MB acknowledge funding by the European Research Council 485 (ERC) under the European Union's Horizon

2020 research and innovation programme (project INTEXseas, grant agreement no. 787652). We thank Mauro Hermann and Matthias Röthlisberger for input and helpful discussions, and Michael Sprenger (all ETH Zurich) for his help with preparing the ERA5 data. KH thanks Katharina Heitmann for feedback on the first draft of the manuscript. The authors acknowledge MeteoSwiss and ECWMF for providing access to the ERA5 reanalyses. 
https://doi.org/10.5194/wcd-2021-18

Preprint. Discussion started: 13 April 2021

(C) Author(s) 2021. CC BY 4.0 License.

\section{References}

Arrhenius, S.: On the influence of carbonic acid in the air upon the temperature of the ground, Philos. Mag. J. Sci., 5, 237-276, https://doi.org/https://doi.org/10.1080/14786449608620846, 1896.

Binder, H., Boettcher, M., Grams, C. M., Joos, H., Pfahl, S., and Wernli, H.: Exceptional air mass transport and dynamical drivers of an extreme wintertime Arctic warm event, Geophys. Res. Lett., 44, 12 028-12 036, https://doi.org/10.1002/2017GL075841, 2017.

Blunden, J. and Arndt, D. S.: State of the Climate in 2016, Bull. Amer. Meteor. Soc., 98, Si-S277, https://doi.org/10.1175/2017BAMSStateoftheClimate.1, 2017.

Boisvert, L. N., Petty, A. A., and Stroeve, J. C.: The impact of the extreme winter 2015/16 Arctic cyclone on the Barents-Kara Seas, Mon. Wea. Rev., 144, 4279-4287, https://doi.org/10.1175/MWR-D-16-0234.1, 2016.

Cohen, J., Screen, J. A., Furtado, J. C., Barlow, M., Whittleston, D., Coumou, D., Francis, J., Dethloff, K., Entekhabi, D., Overland, J., and Jones, J.: Recent Arctic amplification and extreme mid-latitude weather, Nat. Geosci., 7, 627-637, https://doi.org/10.1038/ngeo2234, 2014.

Coy, L. and Pawson, S.: The major Stratospheric Sudden Warming of January 2013: Analyses and forecasts in the GEOS-5 data assimilation system, Mon. Wea. Rev., 143, 491-510, https://doi.org/10.1175/MWR-D-14-00023.1, 2015.

Cullather, R. I., Lim, Y.-K., Boisvert, L. N., Brucker, L., Lee, J. N., and Nowicki, S. M. J.: Analysis of the warmest Arctic winter, 2015-2016, Geophys. Res. Lett., 43, 10 808-10816, https://doi.org/10.1002/2016GL071228, 2016.

615 Curry, J. A., Schramm, J. L., and Ebert, E. E.: Sea ice-albedo climate feedback mechanism, J. Clim., 8, 240-247, https://doi.org/10.1175/1520-0442(1995)008<0240:SIACFM>2.0.CO;2, 1995.

Dickson, R., Lazier, J., Meincke, J., Rhines, P., and Swift, J.: Long-term coordinated changes in the convective activity of the North Atlantic, Prog. Oceanogr., 38, 241-295, https://doi.org/10.1016/S0079-6611(97)00002-5, 1996.

Ding, Q., Schweiger, A., L’Heureux, M., Battisti, D., Po-Chedley, S., Johnson, N., Blanchard-Wrigglesworth, E., Harnos, K., Zhang, Q.,

Eastman, R., and Steig, E.: Influence of high-latitude atmospheric circulation changes on summertime Arctic sea ice, Nat. Clim. Change, 7, 289-295, https://doi.org/10.1038/nclimate3241, 2017.

Gabriel, K. R.: The biplot graphic display of matrices with application to principal component analysis, Biometrika, 58, 453-467, https://doi.org/https://doi.org/10.2307/2334381, 1971.

Gabriel, K. R.: Analysis of Meteorological Data by Means of Canonical Decomposition, J. Appl. Meteorol., 11, 1071-1077, https://doi.org/https://doi.org/10.1175/1520-0450(1972)011<1071:AOMDBM>2.0.CO;2, 1972.

Graf, M. A., Wernli, H., and Sprenger, M.: Objective classification of extratropical cyclogenesis, Q. J. Roy. Meteor. Soc., 143, 1047-1061, https://doi.org/10.1002/qj.2989, 2017.

Graversen, R. G. and Burtu, M.: Arctic amplification enhanced by latent energy transport of atmospheric planetary waves, Q. J. Roy. Meteor. Soc., 142, 2046-2054, https://doi.org/10.1002/qj.2802, 2016.

630 Graversen, R. G. and Wang, M.: Polar amplification in a coupled climate model with locked albedo, Climate Dyn., 33, 629-643, https://doi.org/10.1007/s00382-009-0535-6, 2009.

Harden, B. E., Renfrew, I. A., and Petersen, G. N.: Meteorological buoy observations from the central Iceland Sea, Geophys. Res. Atmos., 120, 3199-3208, https://doi.org/10.1002/2014JD022584, 2015.

Hermann, M., Papritz, L., and Wernli, H.: A Lagrangian analysis of the dynamical and thermodynamic drivers of Greenland melt events during 1979-2017, Weather Clim. Dynam., 1, 497-518, https://doi.org/https://doi.org/10.5194/wcd-2020-16, 2020. 
https://doi.org/10.5194/wcd-2021-18

Preprint. Discussion started: 13 April 2021

(C) Author(s) 2021. CC BY 4.0 License.

Hersbach, H., Bell, B., Berrisford, P., Hirahara, S., Horányi, A., Muñoz-Sabater, J., Nicolas, J., Peubey, C., Radu, R., Schepers, D., Simmons, A., Soci, C., Abdalla, S., Abellan, X., Balsamo, G., Bechtold, P., Biavati, G., Bidlot, J., Bonavita, M., De Chiara, G., Dahlgren, P., Dee, D., Diamantakis, M., Dragani, R., Flemming, J., Forbes, R., Fuentes, M., Geer, A., Haimberger, L., Healy, S., Hogan, R. J., Hólm, E., Janisková, M., Keeley, S., Laloyaux, P., Lopez, P., Lupu, C., Radnoti, G., de Rosnay, P., Rozum, I., Vamborg, F., Villaume, S., and Thépaut, J. N.: The ERA5 global reanalysis, Q. J. Roy. Meteor. Soc., 146, 1999-2049, https://doi.org/10.1002/qj.3803, 2020.

Johannessen, O. M., Kuzmina, S. I., Bobylev, L. P., and Miles, M. W.: Surface air temperature variability and trends in the Arctic: new amplification assessment and regionalisation, Tellus A, 68, 28 234, https://doi.org/10.3402/tellusa.v68.28234, 2016.

Laliberté, F. and Kushner, P. J.: Midlatitude moisture contribution to recent Arctic tropospheric summertime variability, J. Clim., 27, 56935707, https://doi.org/10.1175/JCLI-D-13-00721.1, 2014

Lindsay, R. W.: Temporal variability of the energy balance of thick Arctic pack ice, J. Clim., 11, 313-333, https://doi.org/10.1175/15200442(1998)011<0313:TVOTEB>2.0.CO;2, 1998.

Liu, C. and Barnes, E. A.: Extreme moisture transport into the Arctic linked to Rossby wave breaking, J. Geophys. Res.: Atmos., 120, 3774-3788, https://doi.org/10.1002/2014JD022796, 2015.

Marshall, J. and Schott, F.: Open-ocean convection: Observations, theory, and models, Rev. Geophys., 37, 1-64, https://doi.org/10.1029/98RG02739, 1999.

Martius, O. and Rivière, G.: Rossby wave breaking: climatology, interaction with low-frequency climate variability, and links to extreme weather events, in: Dynamics and predictability of large-scale, high-impact weather and climate events, edited by Li, J., Swinbank, R., Grotjahn, R., and Volkert, H., pp. 69-78, Cambridge University Press, Cambridge, https://doi.org/10.1017/CBO9781107775541.006, 2016.

Messori, G., Woods, C., and Caballero, R.: On the drivers of wintertime temperature extremes in the High Arctic, J. Clim., 31, 1597-1618, https://doi.org/10.1175/JCLI-D-17-0386.s1, 2018.

Nath, D., Chen, W., Zelin, C., Pogoreltsev, A. I., and Wei, K.: Dynamics of 2013 Sudden Stratospheric Warming event and its impact on cold weather over Eurasia: Role of planetary wave reflection, Scientific Reports, 6, 24 174, https://doi.org/10.1038/srep24174, 2016.

Nghiem, S. V., Hall, D. K., Mote, T. L., Tedesco, M., Albert, M. R., Keegan, K., Shuman, C. A., DiGirolamo, N. E., and Neumann, G.: The extreme melt across the Greenland ice sheet in 2012, Geophys. Res. Lett., 39, L20 502, https://doi.org/10.1029/2012GL053611, 2012.

Ohmura, A.: Present status and variations in the Arctic energy balance, Polar Sci., 6, 5-13, https://doi.org/10.1016/j.polar.2012.03.003, 2012.

Olonscheck, D., Mauritsen, T., and Notz, D.: Arctic sea-ice variability is primarily driven by atmospheric temperature fluctuations, Nature Geoscience, 12, 430-434, https://doi.org/10.1038/s41561-019-0363-1, 2019.

Papritz, L.: Arctic lower-tropospheric warm and cold extremes: Horizontal and vertical transport, diabatic processes, and linkage to synoptic circulation features, J. Clim., 33, 993-1016, https://doi.org/10.1175/JCLI-D-19, 2020.

Papritz, L. and Dunn-Sigouin, E.: What configuration of the atmospheric circulation drives extreme net and total moisture transport into the Arctic, Geophys. Res. Lett., 47, e2020GL089 769, https://doi.org/10.1029/2020GL089769, 2020.

Papritz, L. and Spengler, T.: A Lagrangian climatology of wintertime cold air outbreaks in the Irminger and Nordic Seas and their role in shaping air-sea heat fluxes, J. Clim., 30, 2717-2737, https://doi.org/10.1175/JCLI-D-16-0605.1, 2017.

670 Petty, A. A., Stroeve, J. C., Holland, P. R., Boisvert, L. N., Bliss, A. C., Kimura, N., and Meier, W. N.: The Arctic sea ice cover of 2016: a year of record-low highs and higher-than-expected lows, The Cryosphere, 12, 433-452, https://doi.org/10.5194/tc-12-433-2018, 2018.

Pithan, F. and Mauritsen, T.: Arctic amplification dominated by temperature feedbacks in contemporary climate models, Nat. Geosci., 7 , 181-184, https://doi.org/10.1038/ngeo2071, 2014. 
https://doi.org/10.5194/wcd-2021-18

Preprint. Discussion started: 13 April 2021

(C) Author(s) 2021. CC BY 4.0 License.

\section{(c) (i)}

Weather and

Climate Dynamics

Discussions

Pithan, F., Svensson, G., Caballero, R., Chechin, D., Cronin, T. W., Ekman, A. M. L., Neggers, R., Shupe, M. D., Solomon, A., Tjernström, M., and Wendisch, M.: Role of air-mass transformations in exchange between the Arctic and mid-latitudes, Nat. Geosci., 11, 805-812, https://doi.org/10.1038/s41561-018-0234-1, 2018.

Pope, J. O., Bracegirdle, T. J., Renfrew, I. A., and Elvidge, A. D.: The impact of wintertime sea-ice anomalies on high surface heat flux events in the Iceland and Greenland Seas, Clim. Dynam., 54, 1937-1952, https://doi.org/10.1007/s00382-019-05095-3, 2020.

Schweiger, A., Lindsay, R., Zhang, J., Steele, M., Stern, H., and Kwok, R.: Uncertainty in modeled Arctic sea ice volume, J. Geophys. Res., 116, C00D06, https://doi.org/10.1029/2011JC007084, 2011.

Segtnan, O. H., Furevik, T., and Jenkins, A. D.: Heat and freshwater budgets of the Nordic Seas computed from atmospheric reanalysis and ocean observations, J. Geophys. Res., 116, C11 003, https://doi.org/10.1029/2011JC006939, 2011.

Serreze, M. C. and Barry, R. G.: Processes and impacts of Arctic amplification: A research synthesis, Glob. Planet. Change, 77, 85-96, https://doi.org/10.1016/j.gloplacha.2011.03.004, 2011.

Serreze, M. C. and Francis, J. A.: The Arctic amplification debate, Climatic Change, 76, 241-264, https://doi.org/10.1007/s10584-005-9017y, 2006.

Simmonds, I. and Rudeva, I.: The great Arctic cyclone of August 2012, Geophys. Res. Lett., 39, L23709, https://doi.org/10.1029/2012GL054259, 2012.

Sorteberg, A. and Walsh, J. E.: Seasonal cyclone variability at $70^{\circ} \mathrm{N}$ and its impact on moisture transport into the Arctic, Tellus A, 60 , 570-586, https://doi.org/10.1111/j.1600-0870.2008.00314.x, 2008.

Sprenger, M., Fragkoulidis, G., Binder, H., Croci-Maspoli, M., Graf, P., Grams, C. M., Knippertz, P., Madonna, E., Schemm, S., Škerlak, B., and Wernli, H.: Global climatologies of Eulerian and Lagrangian flow features based on ERA-Interim, B. Am. Meteotol. Soc., 98, 1739-1748, https://doi.org/10.1175/BAMS-D-15-00299.1, 2017.

Stroeve, J., Frei, A., McCreight, J., and Ghatak, D.: Arctic sea-ice variability revisited, Ann. Glaciol., 48, 71-81, https://doi.org/10.3189/172756408784700699, 2008.

Talley, L. D.: Freshwater transport estimates and the global overturning circulation: Shallow, deep and throughflow components, Prog. Oceanogr., 78, 257-303, https://doi.org/10.1016/j.pocean.2008.05.001, 2008.

Tyrlis, E., Manzini, E., Bader, J., Ukita, J., Nakamura, H., and Matei, D.: Ural blocking driving extreme Arctic sea ice loss, cold Eurasia, and stratospheric vortex weakening in autumn and early winter 2016-2017, J. Geophys. Res.: Atmos., 124, 11313-11329, https://doi.org/10.1029/2019JD031085, 2019.

Vavrus, S.: The impact of cloud feedbacks on Arctic climate under greenhouse forcing, J. Clim., 17, 603-615, https://doi.org/10.1175/15200442(2004)017<0603:TIOCFO>2.0.CO;2, 2004.

Webster, M. A., Parker, C., Boisvert, L., and Kwok, R.: The role of cyclone activity in snow accumulation on Arctic sea ice, Nat. Commun., 10, 5285, https://doi.org/10.1038/s41467-019-13299-8, 2019.

Wernli, H. and Papritz, L.: Role of polar anticyclones and mid-latitude cyclones for Arctic summertime sea-ice melting, Nat. Geosci., 11, 108-113, https://doi.org/10.1038/s41561-017-0041-0, 2018.

White, D., Hinzman, L., Alessa, L., Cassano, J., Chambers, M., Falkner, K., Francis, J., Gutowski, W. J., Holland, M., Holmes, R. M., Huntington, H., Kane, D., Kliskey, A., Lee, C., McClelland, J., Peterson, B., Rupp, T. S., Straneo, F., Steele, M., Woodgate, R., Yang, D., Yoshikawa, K., and Zhang, T.: The Arctic freshwater system: Changes and impacts, J. Geophys. Res., 112, G04S54, https://doi.org/10.1029/2006JG000353, 2007. 
https://doi.org/10.5194/wcd-2021-18

Preprint. Discussion started: 13 April 2021

(C) Author(s) 2021. CC BY 4.0 License.

Weather and

Climate Dynamics

(c) (i)

Discussions

L

Woods, C. and Caballero, R.: The role of moist intrusions in winter Arctic warming and sea ice decline, J. Clim., 29, 4473-4485, https://doi.org/10.1175/JCLI-D-15-0773.1, 2016.

Woods, C., Caballero, R., and Svensson, G.: Large-scale circulation associated with moisture intrusions into the Arctic during winter, Geophys. Res. Lett., 40, 4717-4721, https://doi.org/10.1002/grl.50912, 2013. 